\title{
Production and on-line comprehension of definiteness in English and Dutch by monolingual and sequential bilingual children
}

Second Language Research 20I5, Vol. 3I(3) 309-34I

(C) The Author(s) 2015

Reprints and permissions: sagepub.co.uk/journalsPermissions.nav DOI: I0.I I77/02676583 |456446 I sir.sagepub.com @SAGE

\section{Vasiliki Chondrogianni}

University of Edinburgh, UK

\author{
Nada Vasić \\ University of Amsterdam, the Netherlands
}

\section{Theodoros Marinis}

University of Reading, UK

\section{Elma Blom}

Utrecht University, the Netherlands

\begin{abstract}
The present article examines production and on-line processing of definite articles in Turkishspeaking sequential bilingual children acquiring English and Dutch as second languages (L2) in the UK and in the Netherlands, respectively. Thirty-nine 6-8-year-old L2 children and 48 monolingual (LI) age-matched children participated in two separate studies examining the production of definite articles in English and Dutch in conditions manipulating semantic context, that is, the anaphoric and the bridging contexts. Sensitivity to article omission was examined in the same groups of children using an on-line processing task involving article use in the same semantic contexts as in the production task. The results indicate that both L2 children and LI controls are less accurate when definiteness is established by keeping track of the discourse referents (anaphoric) than when it is established via world knowledge (bridging). Moreover, despite variable production, all groups of children were sensitive to the omission of definite articles in the on-line
\end{abstract}

\section{Corresponding author:}

Vasiliki Chondrogianni, School of Philosophy, Psychology and Language Sciences, University of Edinburgh, 3 Charles Street, Edinburgh EH8 9AD, UK.

Email: v.chondrogianni@ed.ac.uk 
comprehension task. This suggests that the errors of omission are not due to the lack of abstract syntactic representations, but could result from processes implicated in the spell-out of definite articles. The findings are in line with the idea that variable production in child L2 learners does not necessarily indicate lack of abstract representations (Haznedar and Schwartz, 1997).

\section{Keywords}

child L2 acquisition, definite articles, on-line processing, production

\section{Introduction}

A recurring debate in second language (L2) acquisition research concerns whether or not missing or erroneous production of grammatical morphology indicates lack of abstract representations (e.g. R Hawkins and Chan, 1997 vs. Haznedar and Schwartz, 1997; Lakshmanan and Selinker, 1994). Studies with adult L2 learners have provided mixed results regarding the nature of their grammatical representations (Grüter et al., 2012; Montrul et al., 2008). Production and comprehension studies with L2 children, on the other hand, have suggested that child L2 learners have target-like abstract syntactic representations despite erroneous or missing grammatical morphemes in production (Chondrogianni and Marinis, 2012; Goad and White, 2004; Haznedar and Schwartz, 1997; Ionin and Wexler, 2002; Paradis et al., 2008; Prévost and White, 2000). The majority of the child L2 acquisition studies has examined the verbal domain (Haznedar and Schwartz, 1997; Ionin and Wexler, 2002; Paradis et al., 2008). Studies examining the acquisition of the nominal domain have either focused on the morphosyntactic properties of articles in L2 children (Chondrogianni, 2008; Granfeldt and Schlyter, 2004) or have investigated the influence of the semantic context on the acquisition of articles using production or metalinguistic tasks (Ionin et al., 2009; Serratrice et al., 2011). The studies that have investigated production and comprehension in the same group of children remain a few (Blom and Vasić, 2011; Grüter, 2005; Vasić and Blom, 2011).

The present article builds upon the assumption that on-line comprehension can provide a window into L2 learners' implicit knowledge, as opposed to production, which may be affected by lexical access or retrieval problems (Clahsen, 2008; Marinis, 2010; VanPatten et al., 2012). It addresses the debate regarding whether L2 children's underlying representations remain intact despite variable production by examining production and on-line comprehension of definite articles in different semantic contexts in two very similar groups of Turkish-speaking child L2 learners of English and Dutch in two independent studies across the two languages. By testing two different L2 child populations with the same L1 acquiring two L2s with similar properties, we aim to increase the experimental power of our results and demonstrate whether or not the results are replicable and generalizable across different populations.

\section{Definiteness and articles in English, Dutch and Turkish}

Definiteness is a semantic notion realized cross-linguistically through different linguistic means, e.g. through the use of bound morphemes (case marking in Turkish), word order 
(in Russian), or through free morphemes (definite and indefinite articles in English and Dutch). Focusing on articles, both English and Dutch have definite articles, the in English, and de or het in Dutch, for nouns with common and neuter gender respectively. Regarding their semantic properties, in the present study we adopt the definition of definiteness proposed by Ionin et al. (2004) following Heim (1991), according to which for a Determiner Phrase (DP) to be definite, the speaker and hearer presuppose the existence of a unique entity in the set denoted by the noun phrase (NP). ${ }^{1}$ In this context the definite DP bears the feature [+definite]. Definiteness may be established: (1) via reference to a previously introduced discourse antecedent known by the hearer and speaker using linguistic means, or (2) to a unique entity established via reference to world knowledge. Reference to a previously mentioned discourse antecedent occurs in the anaphoric use of the definite article in examples (1a) and (1b) for English and Dutch respectively.

(1) a. There was a cat in the room. The cat was sitting comfortably on the cushions.

b. Er was een kat in de kamer. De kat zat comfortabel op de kussens.

In these examples, a new entity (cat/kat) is introduced into the discourse in the lead-in sentence through an indefinite expression ( a cat / een kat). In the following sentence, this entity is old information and, therefore, the subsequent mention involves a definite expression (the cat / de kat). Definiteness can also be established via reference to world knowledge, which gives rise to what are called 'first mention definite expressions' (JA Hawkins, 1991). A specific example of a first mention definite expression is in the use of definite articles in (2a) and (2b) for English and Dutch respectively.

(2) a. Mary wanted to eat a banana. She peeled the skin and cut the fruit into slices.

b. Marie wilde een banaan eten. Zij haalde de schil er vanaf en sneed het in kleine stukjes.

In (2), definiteness is not established via discourse reference, that is, the entity (skin/ $s c h i l$ ) is not introduced first through an indefinite description (a skin/een schil) followed by a definite description (the skin/de schil). It is established via the world knowledge (an extra-linguistic operation) that bananas have skin. Since the banana has been introduced into the discourse and skin is a unique part of the banana, skin needs to be introduced with a definite expression. This extra-linguistic operation is called 'bridging' and relies on making inferences regarding the availability of shared world knowledge (Avrutin and Coopmans, 2000; JA Hawkins, 1991; Lyons, 1999) or by a part-whole entailment (Maratsos, 1976). A new referent can be introduced as unique in a particular context (and hence definite) when it is in a bridging relation with a previously established referent. The hearer, then, accommodates the use of a definite expression by deriving its reference from the bridged referent (Avrutin and Coopmans, 2000).

In the present study we investigated the use of definite articles in English and Dutch in the two definite contexts mentioned above (anaphoric and bridging) in children who have Turkish as L1. Turkish is a head-final, agglutinative language without an overt marker for definite articles (Göksel and Kerslake, 2005; Kornfilt, 1997). Turkish has an indefinite article bir which is homophonous with the numeral (Göksel and Kerslake, 2005; Kornfilt, 1997). Note, though, that bir in Turkish does not share the same properties as the 
indefinite article in English. In example (3) the nouns kitap 'book' and dergi 'magazine' are introduced into the discourse using non-case marked nouns. This is in contrast to the English translation, where the indefinite article is used. In the present article, we focus only on definite articles. Therefore, we leave the properties of indefinite articles aside and we only discuss them to the extent that they were relevant for the present study.

In Turkish definiteness interacts with case marking, in that accusative case marked nouns in the object position are definite, and can therefore scramble away from the verb. The accusative case has been suggested to be primarily a marker for specificity in Turkish (Enç, 1991). Accusative case-marked NPs can be accompanied by the indefinite article to denote specific indefinite noun phrases. For example, the sentence bir.INDEF adam-l.ACC yeldr.PAST 'I saw a man' refers to a specific man known to the speaker but not the hearer. In the present study, we only investigated contexts where the accusative case-marked NPs are definite and specific. Examples (3) and (4) below present definite, case-marked noun phrases in an anaphoric and in a bridging context, respectively.

(3) Ayşe kitap ve dergi satın aldı.Öğleden sonra, bahçede kitab-i okudu. Ayșe book and magazine bought. Noon.ABL after, garden.LOC book.ĀCC read.3SG.PAST 'Ayse bought a book and a magazine. She read the book in the garden in the afternoon.'

(4) Ayşe muz yemek istedi. (Muz-un) kabu-ğ-unu soydu ve fruit slices cut. Ayse banana eat wanted. (Banana.GEN) skin.GEN.ACC peeled and meyveyi dilimlere ayırdı. 'Ayse wanted to eat a banana. She peeled the skin (of the banana) and cut the fruit into slices.'

In (3), the noun phrase kitap 'book' is initially introduced into the discourse using an indefinite, non case-marked noun. Its subsequent mention as a definite noun phrase is marked by accusative case, kitabi 'the book'. In (4), the first mention definite expression kabuğunu 'the skin' carries a genitive possessive morpheme, which indicates that the noun kabuk 'skin' is part of the banana ( $m u z$ in Turkish). The noun carries also accusative case, which indicates that the noun is definite.

Turkish learners of English and Dutch as L2 have to acquire that definiteness is grammaticalized in the two target languages via a free morpheme, the definite article, and also to acquire the semantic nuances associated with the use of the definite article.

\section{LI and L2 acquisition of articles in English and Dutch}

The acquisition of definite articles in L1 English and L1 Dutch children has been studied in both naturalistic and experimental studies. L1 English-speaking children produce articles $90 \%$ of the time in obligatory contexts by the age of three (Brown, 1973) and L1 Dutch-speaking children reach this criterion at the age of four (Verbeek et al., 2007). The slight delay in Dutch compared to English may be related to input frequency and morpho-phonological properties of articles in the two languages (gender encoding in Dutch); bare nouns are more frequent in Dutch than in English, making Dutch children less sensitive to the obligatory use of articles (Guasti et al., 2008; Kupisch, 2004; Rozendaal, 2008). The above studies demonstrate that definite articles are acquired early in both languages.

Apart from the emergence of articles as syntactic placeholders, many studies have focused on the acquisition of their semantic properties by L1 English-speaking (Maratsos, 
1976; Schaeffer and Matthewson, 2005; Schafer and de Villiers, 2000) and Dutchspeaking children (Avrutin and Coopmans, 2000; van Hout et al., 2008).

Schafer and de Villiers (2000) examined the production of definite articles in the anaphoric and bridging condition in 3-5-year-old monolingual English-speaking children using an elicitation task based on short stories without props (similar to Maratsos, 1976). The children performed better on the bridging (70\%-90\%) than the anaphoric condition $(24 \%-60 \%)$ and there was a lot of between-group variability that was not related to age. In both conditions, children's errors consisted primarily of omissions $(8 \%-13 \%$ for the bridging; $23 \%-40 \%$ for the anaphoric condition). Children substituted the definite article with the indefinite one more often in the anaphoric compared with the bridging condition. Avrutin and Coopmans (2000) examined the acquisition of the bridging condition in 3-6-year-old Dutch and Russian children using a truth-value judgment task. The 4and 5-year-old children performed almost at ceiling on the true condition and had no problems rejecting the false sentences. ${ }^{2}$ The above studies indicate that the semantic conditions that regulate article acquisition seem to affect the L1 children's article production at least until the age of five years (but for semantic effects in older children, see Kupisch and Pierantozzi, 2010).

To date studies have examined the acquisition of English articles by sequential bilingual children (Ionin et al., 2009; Zdorenko and Paradis, 2008, 2011). The majority of these studies have examined whether or not L2 children whose L1 does not express definiteness via the use of definite and indefinite articles overuse the definite article the in indefinite specific contexts, where the indefinite article $a$ would be required in English (see Ionin et al., 2004, 2009 for a comprehensive overview). In the present study, we did not focus on the interplay between definiteness and specificity in the L2 acquisition of English and Dutch articles. Rather, the focus of this study was whether or not L2 children's production and omission of definite articles is influenced by subtle semantic distinctions, as it has been reported for L1 children (Schafer and de Villiers, 2000), and whether or not L2 children were sensitive to the grammatical violations involving article omission in an on-line processing task depending on the different semantic contexts. Crucially, the definite contexts that we examined in the anaphoric and the bridging conditions were both definite and specific. These contexts have been reported to elicit few substitution errors of the definite article with the indefinite in L2 children (Ionin et al., 2009).

In this respect, two studies that are relevant for the present article are those of Zdorenko and Paradis $(2008,2011)$ because they examined definite article production in an anaphoric context and included children whose L1s do not grammaticalize articles. Zdorenko and Paradis (2008) administered a narrative task to 17 L2 children in five consecutive rounds with six months between each round. The L2 children were divided in a [+article] group, if their L1 had articles (e.g. Spanish), and in a [-article] group, if their L1 lacked articles (e.g. Chinese). The results from the first round and after nine months of exposure showed that the L2 children from the [-article] group omitted significantly more definite articles compared with the L2 children from the [+article] group. However, the two L2 groups did not differ in definite article omission in the following four rounds. With increasing exposure children's errors consisted primarily of substitutions of the indefinite article with the definite. These results were confirmed in the Zdorenko and Paradis (2011) study with a larger group of L2 children. 
The above studies suggest that child L2 learners initially omit articles, but are later able to converge to the target system, exhibiting an acquisition pattern similar to that of the L1 children (Zdorenko and Paradis, 2008). However, in the Zdorenko and Paradis studies $(2008,2011)$ articles were elicited using a narrative picture-based task and the definite articles were examined only in their anaphoric use. The visual presentation of the characters in the story may have facilitated definite article production because the presence of a picture renders the character familiar, and thus definite, without manipulating linguistic context (Ionin et al., 2009). In our study, definite articles were examined in two different semantic contexts, in the anaphoric, as in the Zdorenko and Paradis studies, but also in the bridging context. Furthermore, to elicit articles we used an elicitation task with short stories followed by questions with no picture props, which is similar to Schafer and de Villiers (2000). Therefore, our study is novel in exploring the effects of semantic context in child L2 acquisition using a methodology that has not been previously used with child L2 learners and by extending this methodology to a new language, Dutch, whose properties in terms of definiteness are similar to that of English.

\section{Production vs. on-line comprehension}

We assume that to acquire articles both L1 and L2 learners need to map features onto forms. According to generative accounts of grammar (Chomsky, 1993), phonological, formal and semantic features are the primitive units out of which lexical items are built; each language selects its feature set out of a universal feature inventory. Children acquiring their L1 select out of this universal inventory the subset of features that are specific to their language. These selected features are assembled into morpho-phonological exponents (lexical units) that feed into computations and form syntactic representations (Halle and Marantz, 1993; Lardiere, 2009).

The assembly of features in L1 acquisition is compatible with the Feature (Re-) assembly account proposed by Lardiere $(2005,2009)$ for L2 acquisition. In this account, L2 learners have to select and (re-)assemble the L1 features into features that are available in the L2 and map them onto the appropriate morpho-phonological exponents. In terms of the acquisition of definite articles by Turkish child L2 learners of English and Dutch, they have to select and re-assemble the [+definite] feature from the Turkish morpho-phonological exponents (accusative case) and map it onto the morpho-phonological exponents of the L2, i.e. the definite article in both the anaphoric and bridging contexts. ${ }^{3}$

Lardiere's feature (re-)assembly account is compatible with theories of L2 acquisition that postulate a dissociation between morphology and syntax, such as the Missing Surface Inflection Hypothesis (MSIH; Haznedar and Schwartz, 1997; Lakshmanan and Selinker, 1994; Lardiere, 1998a; Lardiere, 1998b; Prévost and White, 2000). According to the MSIH, L2 learners' optional or erroneous production does not necessarily indicate lack of abstract representations or features; these errors may reflect errors related to the production system. According to production models (Levelt, 1989), syntactic structures are built up during the grammatical encoding stage based on abstract features that, in turn, select lemmas in the mental lexicon. Selection of lemmas leads to activation of their morpho-phonological properties. Inflectional morphemes are added to structural 
positions that include abstract features. Difficulties in lexical access and retrieval of inflectional morphemes from the mental lexicon can lead to errors of omission even when abstract features are represented in the syntactic structure. L2 learners may have acquired abstract representations including mappings between abstract features and their morpho-phonological exponents in the L2, but during the speeded and highly automatized process of production, they may be unable to access the morpho-phonological exponents or retrieve them from the mental lexicon (VanPatten et al., 2012; White, 2003).

Evidence for the MSIH has been provided from studies investigating production (Lardiere, 2009), off-line comprehension (Grüter, 2005), and grammaticality judgment (Ionin and Wexler, 2002; Paradis et al., 2008). More recently, studies have used production along with on-line comprehension tasks in L2 children to address whether problems in the production of morphology are surface problems, as the MSIH would suggest, or whether they are caused by the lack of underlying representations (Blom and Vasić, 2011; Chondrogianni and Marinis, 2012; Vasić et al., 2012). These studies have shown that sensitivity to grammatical violations may depend on the structure tested. Chondrogianni and Marinis (2012) compared the production and on-line processing of tense morphology by 6-8-year-old L2 English children. The study showed that although children had variable production of tense morphology, they were able to process the ungrammaticality induced by the omission of tense morphemes in an on-line word-monitoring experiment. The sensitivity to the omission of tense morphemes was taken to demonstrate that L2 children have intact underlying representations and omit tense morphemes due to difficulties in the production system.

Blom and Vasić (2011) examined the on-line processing of Dutch determiner-noun agreement in Turkish children acquiring Dutch as their L2 and found sensitivity to gender mismatches for diminutive nouns where gender is morpho-phonologically expressed, but no sensitivity for root nouns, where gender is not morpho-phonologically expressed. Blom and Vasić (2011) argued that L2 children's reliance on morpho-phonology could point to the presence of lower-level form-function associations, and that more abstract gender representation might be unavailable to the L2 children in their study. However, the L2 children in the same study demonstrated sensitivity to gender mismatches in the diminutive condition, even though their performance in production with diminutives was low. This finding supports the idea that L2 children may be able to process the erroneous use of grammatical morphemes despite showing variable production of the same morphemes, as the MSIH would argue.

Another account that attributes problems with L2 morphemes to post-syntactic operations is the Prosodic Transfer Hypothesis (PTH) proposed by Goad and White (2004, 2006). In this account, problems with L 2 morphology are a reflection of how morphological information is prosodically organized in the L2 in relation to the types of prosodic structures available from the L1. In Turkish, definiteness is expressed through accusative case, a word final morpheme which attaches to the right edge of the stem and appears within the Phonological Word (PWd), as in (5a). In contrast to Turkish, definite articles in English and in Dutch are free clitics (Guasti et al., 2008), which appear on the left edge of the PWd and link higher in the tree, at the Phonological Phrase level (PPh) (Nespor and Vogel, 1986; Selkirk, 1986), as in (5c). Interestingly, the indefinite article bir in 
Turkish is considered an affixal clitic which attaches outside the PWd level but not at the PPh level (Goad and White, 2004), as in (5b). ${ }^{4}$

According to this analysis, free clitics are not permitted in Turkish at either edge, whereas they are permitted at the left edge in English and Dutch. However, according to

(5)

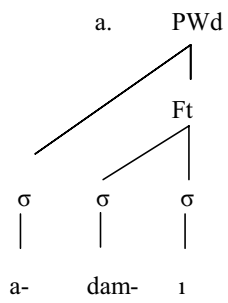

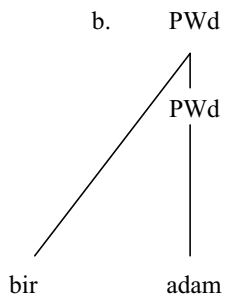

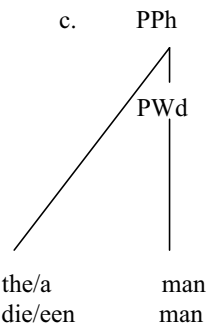

Goad and White (2004), the Turkish L2 learner of English (or Dutch) should be able to conform to the L2 prosodic representation (5c) via a left adjunction process that is already present in the L1 for affixal clitics, i.e. (5b). ${ }^{5}$ Crucially, what is important for the $\mathrm{PTH}$ is how functional material is organized into prosodic structure in the L1 and the L2; whether or not a particular functional category is overtly realized in the L1 is irrelevant. In Goad and White (2004) the predictions of the PTH were partly confirmed as the adult Turkish L2 learner of English had more omissions in the context of the indefinite compared to the definite article, even though both articles share the same prosodic structure, and Turkish has an indefinite article bir.

The present study addresses whether L2 children's difficulties with definite articles are post-syntactic, as the MSIH and the PTH would suggest, and whether L2 children can re-assemble their L1 features according to the L 2 properties by investigating the acquisition of definite articles in child L2 learners of English and Dutch using a production and an on-line comprehension task.

\section{Present study}

This study examined the production and on-line comprehension of definite articles in different semantic contexts by L2 English-speaking children tested in the UK and by L2 Dutch-speaking children tested in the Netherlands. The L1 of the L2 children was Turkish. English and Dutch definite articles share similar semantic properties. If we observe similar effects of semantic contexts in L2 English-speaking and L2 Dutchspeaking children, then the robustness of our findings will substantially increase.

The first aim of the study was to examine whether the semantic context, in which the definite articles occur, influences L2 children's acquisition of definite articles, in the same way as it has been reported in L1 children's acquisition of definite articles. The second aim was to investigate whether or not L2 children whose L1 Turkish does not grammaticalize definiteness in the form of articles, have difficulties with definite articles in production and whether this extends also to on-line comprehension. This 
has important implications for L2 theories and can provide evidence for the three hypotheses relevant to our study, the MSIH, the Feature (Re-)assembly hypothesis and the PTH. In line with these two goals, the study addresses the following research questions:

1. Is the production and processing of definite articles affected by semantic context in L2 children and L1 controls?

2. Are L2 children (and L1 controls) who omit definite articles in production sensitive to the ungrammaticality induced by definite article omission in an on-line comprehension task?

The first prediction relates to the effect of semantic context. In the anaphoric use of articles, the learner is required not only to have definite articles as part of their grammar, but also to be able to implement this grammatical knowledge by keeping track of and assigning reference through linguistic means at the discourse level. This is in contrast with the way definiteness is established in the bridging condition. In this condition, there are no requirements to keep track of and maintain discourse reference; rather, the learner can use a definite expression to refer to a unique entity that is entailed by the presence of another entity via world knowledge, e.g. banana-skin. L1 and L2 children have been shown to have problems with keeping track of and maintaining discourse properties (Serratrice et al., 2011; Sorace et al., 2009), whereas bridging as a semantic computation has been shown to be acquired early on (Avrutin and Coopmans, 2000). This difference is predicted to give rise to an asymmetry in the acquisition of the two semantic conditions; children should show lower performance on the anaphoric compared with the bridging condition. Schafer and de Villiers (2000) found such an asymmetry for L1 children. Our expectation is that this would be the same for L2 children.

The second prediction refers to the comparison between production and on-line comprehension. If Turkish child L2 learners of English and Dutch are able to re-assemble the L1 features onto the morpho-phonological exponents of the two L2s, then we expect them to show high performance in the production of articles and be sensitive to the errors of omission in the on-line comprehension task. However, both the Feature (re-)assembly and the MSIH predict a possible asymmetry between production and comprehension. L2 children may have variable article production, but may be able to detect the ungrammaticality induced by article omission in the on-line comprehension task. This would indicate that the children have managed to re-assemble the L1 morpho-syntactic features according to the L2 properties, but omission errors in production reflect difficulties in lexical access and/or retrieval. We addressed this prediction by comparing children with high and low article production on their sensitivity to grammaticality in the on-line comprehension task. An asymmetry between production and on-line comprehension would also be predicted by the PTH. However, the PTH would also predict that there would be no difference between the two semantic conditions because both contexts involve the use of definite articles; the re-assembly takes place at the level of prosodic structure regardless of the syntactic and/or semantic properties in the L1 and the L2. In the present study we tested these predictions by keeping the L1 constant and by examining two L $2 \mathrm{~s}$ with similar definiteness properties. 
Table I. Information about the English-speaking and Dutch-speaking LI and L2 children's age and performance on the English and the Dutch grammar and vocabulary baseline assessments.

\begin{tabular}{llllll}
\hline English study & $n$ & & Age & TROG & BPVSII \\
\hline L2 children & 22 & Mean & $7 ; 6$ & 9.8 & 61 \\
& & Range & $6 ; 0-8 ; 5$ & $3-18$ & $39-97$ \\
& & SD & 7.7 & 3.8 & 14.4 \\
LI children & 28 & Mean & $7 ; 5$ & 14.7 & 90.9 \\
& & Range & $6 ; 0-8 ; 6$ & $8-19$ & $61-119$ \\
& & SD & 7.7 & 2.7 & 12.4 \\
\hline Dutch study & $\mathrm{N}$ & & Age & TAK-grammar & TAK-vocabulary \\
\hline L2 children & I7 & Mean & $7 ; 6$ & 31.8 & 63.9 \\
& & Range & $6 ; 1-8 ; 10$ & $24-38$ & $42-84$ \\
& & SD & 7.7 & 3.8 & 9.87 \\
LI children & 20 & Mean & $7 ; 2$ & 34.9 & 79.7 \\
& & Range & $6 ; 4-8 ; 11$ & $30-42$ & $68-90$ \\
& & SD & $7 ; 2$ & 3.3 & 5.8 \\
\hline
\end{tabular}

Notes. TROG: Test for Reception of Grammar (Bishop, 2003); BPVS: British Picture Vocabulary Scale (Dunn et al., 1997). TAK: Taaltoets Alle Kinderen (TAK; Verhoeven and Vermeer, 200I). The numbers under all assessments represent raw scores.

\section{Methodology}

Table 1 shows the L1 and the L2 children's biodata, as well as their scores on the English and Dutch baseline assessments used in the English and the Dutch studies.

a English study. The L1-Turkish L2-English children were recruited from primary schools in London and the L1 children through the University of Reading Child Development Database. A parental questionnaire (Chondrogianni and Marinis, 2011) was administered to examine the L2 children's language history and status, age of onset $(\mathrm{AoO})$ and length of exposure (LoE), as well as quantity and quality of input in English. All L2 children's parents and caregivers were Turkish-speaking. L2 children's systematic exposure to English began with attendance of pre-school education around the age of three years. The L2 children had a mean age of onset between 2;5 and 4 years and their exposure to English was three years on average. The Test of Reception of Grammar 2 (Bishop, 2003) and the British Picture Vocabulary Scales II (Dunn et al., 1997) were used to examine the children's general grammatical and vocabulary abilities. In the present study, the L1 and L2 children were matched on age $(p>.1)$. Therefore, the raw scores were used to compare the children's abilities (Table 1). Two one-way ANOVAs revealed that the L2 children were less accurate than the L1 children in both tasks (TROG2: $\mathrm{F}(1,49)=70.81, \mathrm{p}<.001, \eta_{\mathrm{p}}{ }^{2}=.66$; BPVSII: $\mathrm{F}(1,49)=$ $\left.89.73, \mathrm{p}<.001, \eta_{\mathrm{p}}^{2}=.52\right)$.

b Dutch study. All L1-Turkish L2-Dutch children's parents and caregivers were Turkish-speaking, and the children's systematic exposure to Dutch began with attendance of 
pre-school education at the age of 2;6 years on average. Length of exposure to Dutch was five years on average. The two groups were matched on chronological age $(\mathrm{F}(1,36)$ $=3.79, \mathrm{p}>.05$ ). All participants came from the western part of the Netherlands (Randstad). Dutch language abilities were assessed using the receptive grammar and vocabulary subtest of the standardized test Taaltoets Alle Kinderen (TAK; Verhoeven and Vermeer, 2001). L2 children scored less well than L1 children in both receptive gram$\operatorname{mar}\left(\mathrm{F}(1,36)=8.53, \mathrm{p}<.05, \eta_{\mathrm{p}}^{2}=.02\right.$; raw scores $)$ and vocabulary $(\mathrm{F}(1,36)=36.33, \mathrm{p}$ $<.001, \eta_{\mathrm{p}}^{2}=.50$; raw scores).

\section{Production task}

To assess L1 and L2 children's article production, we created a production task with a format similar to the Diagnostic Evaluation of Language Variation (DELV) (Seymour et al., 2005). In this task, the experimenter read out short stories to the child without using any pictures or props. In the English experiment, each story was followed by a question to elicit definite noun phrases in the object position and definite articles in different semantic contexts. ${ }^{6}$ In the Dutch experiment, we used a sentence completion prompt instead of a question to test the same semantic contexts as in English; the target noun was embedded in a prepositional phrase. ${ }^{7}$ English and Dutch definite articles were elicited in two contexts: the anaphoric, as in (6a and b) and the bridging, as in (7a and b) for English and Dutch respectively.

(6) Anaphoric condition

a. Experimenter: Mary has a doll and a painting. She played with one of them. Guess which. Child (expected answer): The doll.

b. Experimenter: Marian heeft een appel en een bloem. Van een ding neemt ze een hapje. Marian neemt een hapje ...

Experimenter: Marian has an apple and a flower. She takes a bite of one of the two. Marian takes a bite ...

Child (expected response): van de appel.

Child (expected response): of the apple.

(7) Bridging condition

a. Experimenter: Sally wanted to eat a banana, but first she needed to peel something off it. What did Sally need to peel off?

Child (expected answer): The skin.

b. Experimenter: De fiets van Sander is kapot. Er zit ergens een gaatje in. Er zit een gaatje ... Experimenter: Sander's bike is broken. There is a hole in something. There is a hole ... Child (expected response): in de band.

Child (expected response): in the tire.

In the English study, in the anaphoric condition, the target noun was initially introduced into the discourse with an indefinite article and then it was elicited using the question 'Guess which'. In the bridging condition, the noun in the story and the target noun were strongly associated through a 'part-whole' relation. The noun that denoted the whole set from the whole-part relation was presented first. The noun that denoted the 'part' was then elicited with the question What ...? 
All nouns in both studies were inanimate. In the English experiment, the nouns in the anaphoric condition were book, car, poster, doll, shirt, train, and in the bridging condition they were skin, lid, door, engine, wheel, window. The nouns in the anaphoric and the bridging conditions were matched for frequency, length (number of syllables) and age of acquisition (below 6; MRC Psycholinguistic Database, 1997). There were 6 items in each condition (anaphoric, bridging), and 12 filler items, giving rise to 24 items in total. In the Dutch experiment, the elicited nouns in the definite anaphoric condition were: krant 'newspaper', auto 'car', appel 'apple', pop 'doll', spiegel 'mirror, pizza 'pizza', bril 'glasses', stoel 'chair' and in the definite bridging: schil 'peel', deur 'door', band 'tire', dop 'lid', glijbaan 'slide', schoorsteen 'chimney', (kerk)toren 'tower', leuning 'railing'. All nouns were mono- and bi-syllabic words with an age of acquisition below 6 years of age (Damhuis et al., 1992; Schlichting and Lutje Spelberg, 2002). There were 8 items per condition (anaphoric, bridging) and 16 filler items, giving rise to 32 items in total. We also controlled the gender of the nouns elicited, which had all common gender requiring the definite determiner 'de'. Common gender is acquired early in both child L1 and child L2 Dutch, in contrast to neuter gender (Blom et al., 2008; Cornips and Hulk, 2008; among others), and was chosen to avoid task difficulties due to problems with neuter grammatical gender.

Responses involving a definite article and the target noun were coded as 'correct'. Responses involving an indefinite article with the target noun were coded as 'substitutions'. Responses with bare (articleless) target nouns were coded as 'omissions'. If a child produced a noun with or without an article, which was not already mentioned in the story in the case of the anaphoric condition, or which was not a member of the partwhole relation in the bridging condition, the response was coded as 'other' and was excluded from the final calculation. In the English study, this amounted to $17 \%$ of the data and in the Dutch study to $13 \%$ of the data. Proportion correct, substitutions and omissions were calculated out of all three response types (denominator: correct, substitutions and omissions).

a Self-paced listening task. To assess L1 and L2 children's sensitivity of omission of definite articles in the anaphoric and bridging conditions, we used an on-line selfpaced listening task in which half of the sentences were grammatical and included definite articles and the other half contained article omissions (indicated in brackets in the examples below), as in (8a and b) and (9a and b) for English and Dutch respectively.

(8) Anaphoric condition

a. The bear bought a book and a magazine. The bear / read / (the) book / in his garden / at lunchtime.

b. Peter heeft een krant gekocht. Peter / leest / (de) krant / in zijn tuin / 's ochtends vroeg. 'Peter has bought a newspaper. Peter / is reading / (the) newspaper / in his garden / early in the morning.'

(9) Bridging condition

a. The monkey wanted to eat a banana but first he had to remove something. The monkey / removed / (the) skin / of the banana / at lunchtime. 
b. Jannie wil haar banaan opeten, maar eerst moet ze iets doen. Jannie / haalt / (de) schil / van de banaan / met een mesje.

'Jannie want to eat her banana, but she must do something first. Jannie / takes / (the) peel / off the banana / with a knife.'

In both the English and the Dutch experiments, all critical sentences had an SVO structure followed by two prepositional phrases (segments 4 and 5 in sentences (8) and (9) above). All critical nouns appeared in the object position (Segment 3) and were inanimate. There were 8 critical nouns per sentence type. In both experiments, the nouns in the on-line experiment comprised the 12 inanimate nouns used in the production task plus two more inanimate nouns in the English study. The verbs in the pre-critical segments and the nouns in the critical and the post-critical segments were matched between the two conditions for frequency, length, and age of acquisition (below 6 years of age). There were 8 items per condition, giving rise to 32 experimental sentences. There were also 32 filler items, involving indefinite noun phrases and subject-verb agreement contexts, giving rise to 64 experimental trials in total. A third of the items was followed by general comprehension questions targeting elements of the sentence that were not related to the experimental conditions, such as Was the bear reading in the garden?, to ensure that the children were attending to the task.

Each participant encountered the grammatical and ungrammatical version of each sentence in a single-case design in two different lists presented in weekly intervals. The presentation of the lists was randomized across participants in order to address any order of presentation effects. The experimental session was preceded by a practice session in which the children were familiarized with the task. To proceed to the experimental session, children had to successfully complete the practice session, which could be repeated twice. All children successfully completed the practice session. Children wore headphones while completing the on-line processing task to increase attention and minimize external noise. The administration of the task was controlled by the experimenter and children were able to take a break from the task at any point, if they wished to.

b Procedure. Each child participated in three sessions. The sessions took place in a quiet room at the children's schools. In the first session, the baseline and production tasks were administered. In the subsequent two sessions the on-line processing tasks were carried out. The production task always preceded the on-line comprehension task to avoid making participants aware of the phenomena by exposing them to the ungrammatical sentences within the on-line processing tasks.

\section{Results}

To calculate within-participants effects across the three groups we used repeated-measures ANOVAs. For all ANOVAs, effect sizes were computed using partial eta-square $\left(\eta_{\mathrm{p}}{ }^{2}\right)$. Post-hoc tests were calculated using Bonferroni correction. To unpack interactions, we ran paired-samples t-test for each group separately. To compare the two groups, independent samples t-tests were used. 


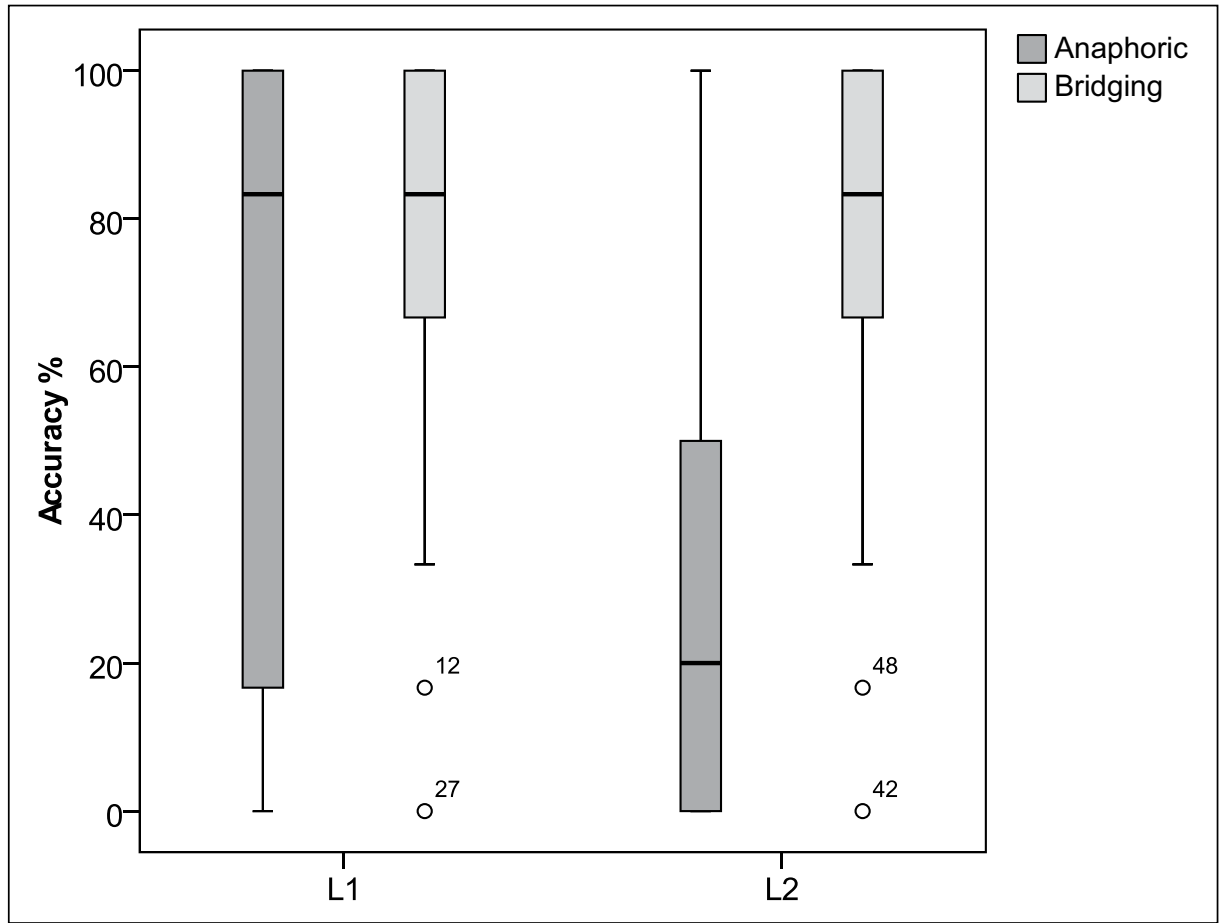

Figure I. Accuracy (\%) on the definite articles in the anaphoric and the bridging conditions by the English-speaking LI and L2 children.

\section{Production task}

Figures 1 and 2 show the children's performance in the production task in the anaphoric and the bridging conditions in the English and Dutch studies respectively. To examine whether or not the L2 children differed from the L1 children in terms of article production, we used a repeated-measures ANOVA with Context (anaphoric, bridging) as the within participants factor and Group (L1, L2) as the between participants factor in both studies.

In the English study, this revealed a main effect of Context $(\mathrm{F}(1,47)=40.27, \mathrm{p}<.001$, $\left.\eta_{\mathrm{p}}{ }^{2}=.46\right)$, a trend towards a main effect of Group $\left(\mathrm{F}(1,47)=3.18, \mathrm{p}=.08, \eta_{\mathrm{p}}{ }^{2}=.06\right)$, and an interaction between Context and Group $\left(F(1,47)=10.69, p<.01, \eta_{p}{ }^{2}=.19\right)$, showing that the two groups differed in their accuracy depending on context.

Paired samples t-tests suggested that both groups were more accurate in the bridging vs. the anaphoric condition $(\mathrm{L} 1: \mathrm{t}(27)=-2.40, \mathrm{p}=.02 ; \mathrm{L} 2: \mathrm{t}(20)=-6.20, \mathrm{p}<.001)$, but after assessing the outcomes against an alpha level of decision corrected for multiple comparisons $(.05 / 4=.0125)$ the effect in the L1 group was not retained and can only be interpreted as a trend. The two groups did not differ in their performance in the bridging condition $(\mathrm{t}(47)=-1.84, \mathrm{p}=.86)$, but the L2 children were less accurate than the L1 children in the anaphoric condition $(\mathrm{t}(47)=2.89, \mathrm{p}<.01)$. 


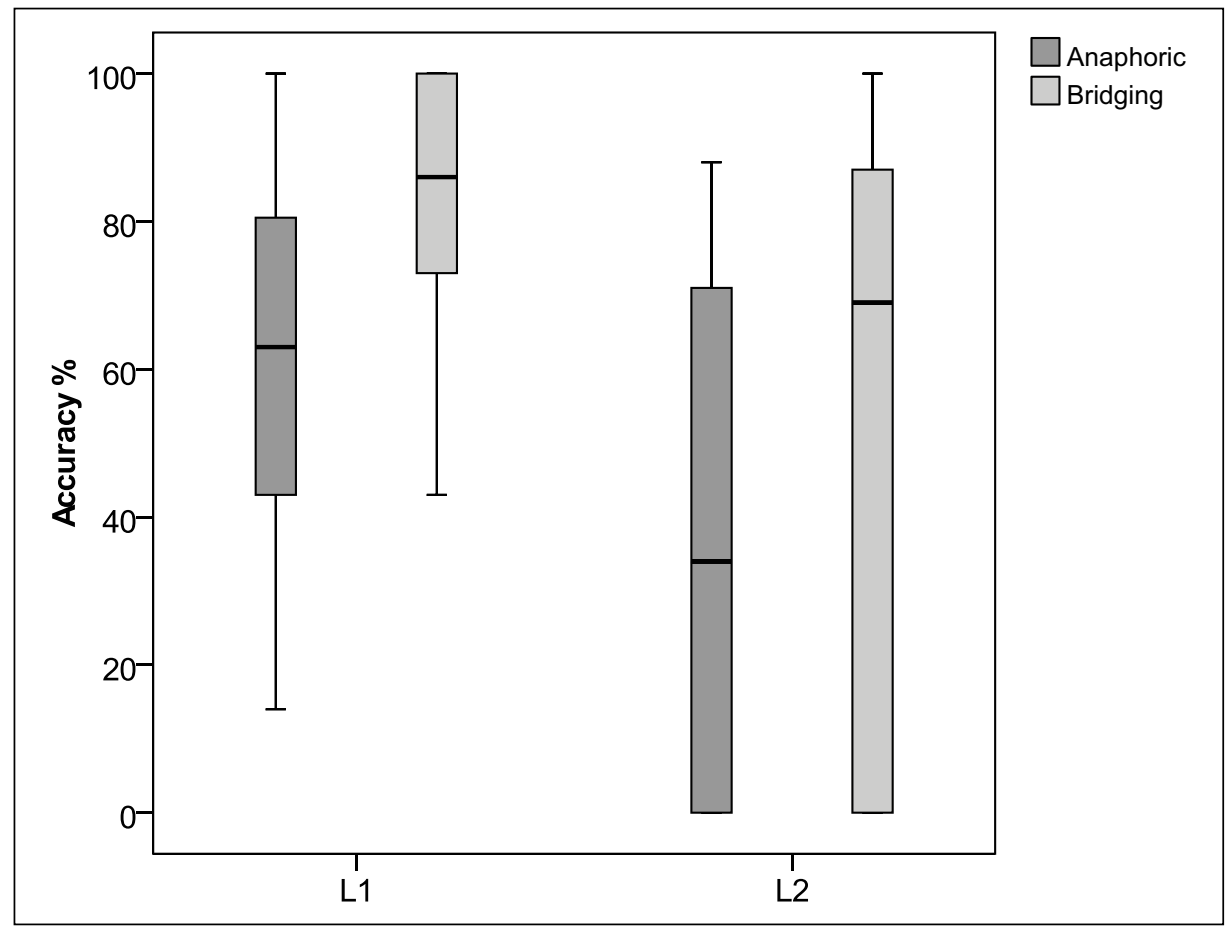

Figure 2. Accuracy (\%) on definite articles in the anaphoric and the bridging conditions by the Dutch-speaking LI and L2 children.

In the Dutch study, the same analysis revealed that the bridging condition was significantly more accurate than the anaphoric condition $\left(\mathrm{F}(1,34)=23.70, \mathrm{p}<.001, \eta_{\mathrm{p}}{ }^{2}=\right.$ $.41)$, and that the L1 group was more accurate than the L2 group $(F(1,34)=9.25, p<$ $\left..01, \eta_{\mathrm{p}}^{2}=.21\right)$.

Figures 3 and 4 present the proportion of substitution and omission errors in the anaphoric and the bridging conditions by the L1 and the L 2 children in the English and the Dutch study respectively.

To examine whether the different semantic conditions elicited different error types and whether L2 children differed from the L1 we conducted a repeated measures ANOVA with Error as the within participants variable and Group as the between participants factor in both studies.

For English, visual inspection of Figure 3 indicates that in both groups, omission is the predominant error type. The statistical analysis confirmed that omission errors outnumbered substitution errors $\left(F(1,47)=25.36, \mathrm{p}<.001, \eta_{\mathrm{p}}{ }^{2}=.35\right)$. The effect of Group approached significance, indicating that the L2 group tended to make more omission and substitution errors than the L1 group $\left(\mathrm{F}(1,47)=3.61, \mathrm{p}=.06, \eta_{\mathrm{p}}{ }^{2}=.07\right)$.

For Dutch, the statistical analysis showed a significant interaction effect between Error and Group $\left(\mathrm{F}(1,34)=5.74, \mathrm{p}<.05, \eta_{\mathrm{p}}{ }^{2}=.14\right)$. Subsequent independent samples t-tests revealed that the $\mathrm{L} 2$ group omitted definite articles more often than the L1 group 


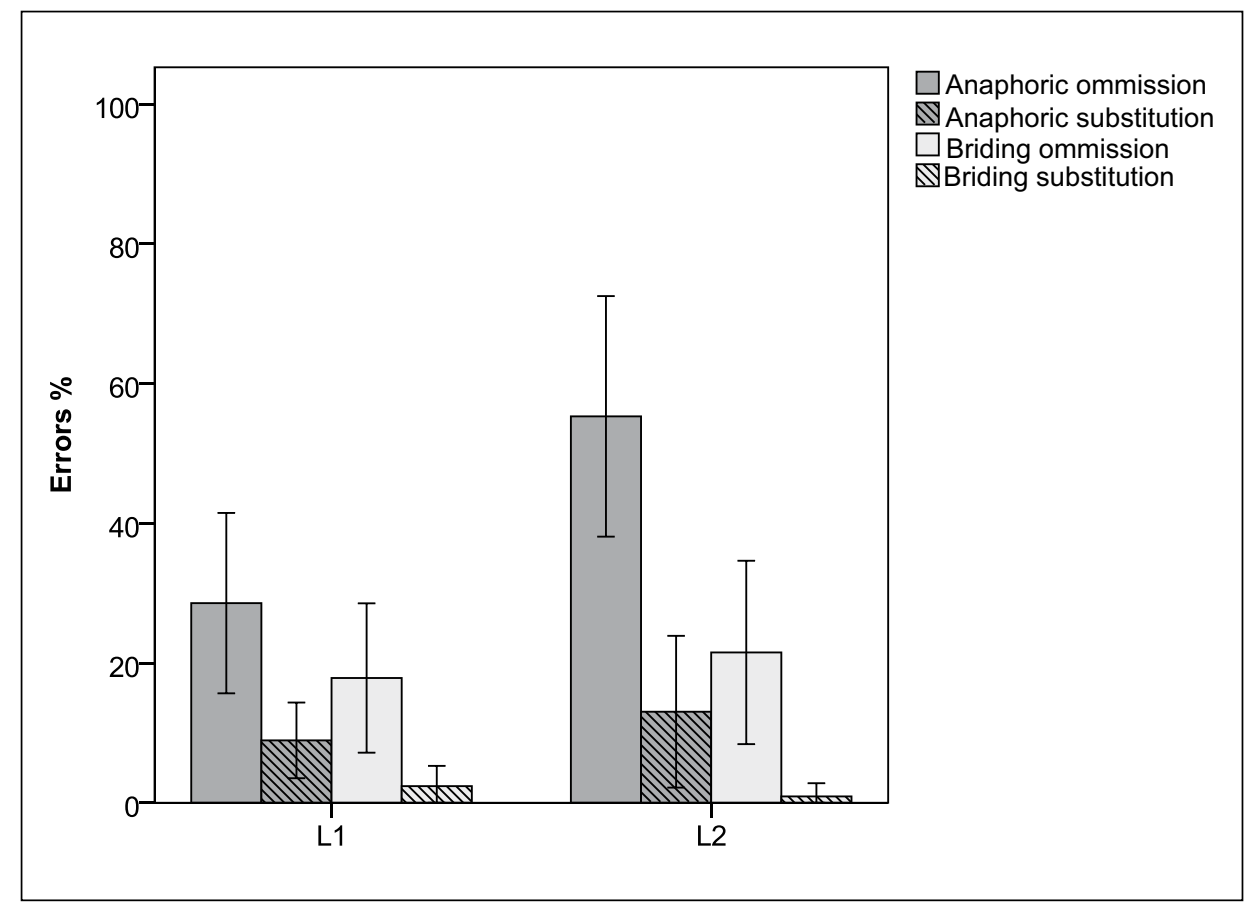

Figure 3. Substitution and omission errors (\%) in the anaphoric and the bridging conditions by the English-speaking LI and L2 children.

$\operatorname{did}(\mathrm{t}(19)=2.8, \mathrm{p}=.01$; equal variance not assumed because Levene's test for equality of variances was significant), whereas no between-group difference emerged for substitutions $(\mathrm{t}(35)=-.35, \mathrm{p}=.72)$.

The error bars in Figures 3 and 4 indicate substantial individual variation in error types. After presenting the self-paced listening results, we will further look into individual variation with respect to omission errors and relationships between individual variation in production and on-line comprehension.

\section{Self-paced listening task}

Prior to calculating RTs, we calculated children's accuracy on the comprehension questions in the experiment. Items with erroneous responses to comprehension questions were excluded from the analyses of RTs. In both studies, the L1 children were more accurate in the comprehension questions (English study: mean: 89.5\%, SD: 4.9, range: 79\%-97\%; Dutch study: mean: $96.4 \%$, SD: 3.6, range: $91.1 \%-100 \%$ ) than the L2 children (English study: mean: 79.3\%, SD: 2.2, range: 59\%-97\%; Dutch study: $90.1 \%$, SD: 8.3, range: $73.5 \%-100 \%$ ). Two one-way ANOVAs revealed that the two groups differed in terms of accuracy on the comprehension questions in both studies (English: $(\mathrm{F}(1,48)$ $\left.=22.63, \mathrm{p}<.001, \eta_{\mathrm{p}}{ }^{2}=.21\right)$; Dutch: $\left(\mathrm{F}(1,35)=11.96, \mathrm{p}<.001, \eta_{\mathrm{p}}{ }^{2}=.21\right)$. 


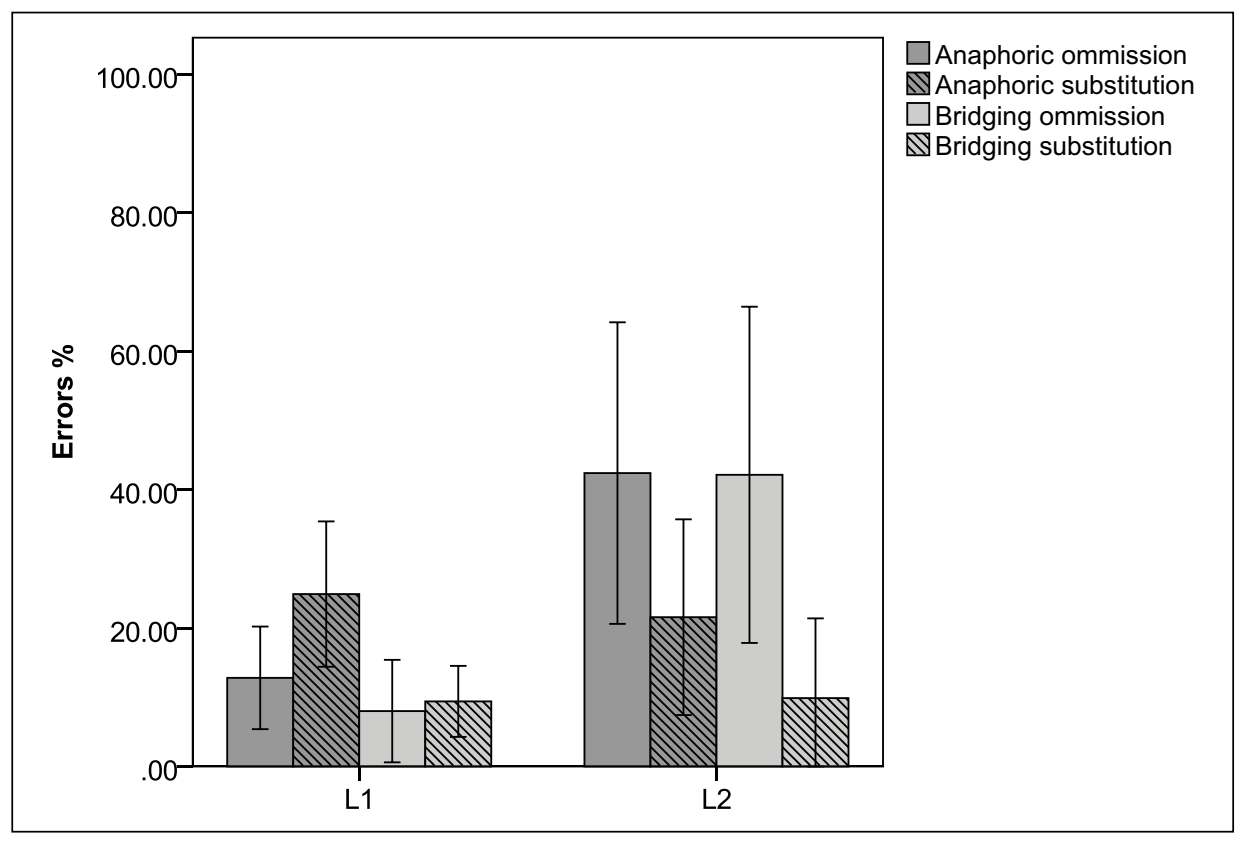

Figure 4. Substitution and omission errors (\%) in the anaphoric and the bridging conditions by the Dutch-speaking LI and L2 children.

To control for the difference in length between the critical segments in the grammatical and ungrammatical conditions, raw RTs were transformed into residual RTs by subtracting from the raw RTs the duration of the audio file for each segment separately. Extreme values were calculated using the boxplot procedure of SPSS. Residual RTs above $2,000 \mathrm{~ms}$ were excluded from the final calculation as extreme values. Outliers were defined as RTs of 2 standard deviations above and below the mean RTs per condition per subject and per item. In the English study, the total number of extreme values and outliers was $4.5 \%$ for the L2 children, $4.6 \%$ for the L1 children. In the Dutch study, the total number of extreme values and outliers was $4 \%$ for the L 2 children and $3 \%$ for the $\mathrm{L} 1$ children.

a English study. The residual RTs for the grammatical and ungrammatical conditions for the definite article in the anaphoric and bridging contexts for the L1 and the L2 children are presented in Figures 5 to 8 respectively. To examine whether L1 and L2 children were sensitive to the ungrammaticality due to article omission, we ran a repeated-measures ANOVA with Context (anaphoric, bridging) and Grammaticality (grammatical, ungrammatical) as the within participants factors and Group (L1, L2) as the between participants factor in a per participants $\left(\mathrm{F}_{1}\right)$ and a per items $\left(\mathrm{F}_{2}\right)$ analysis for each segment separately.

For the pre-critical segment (Segment 2), the L2 children showed shorter RTs than the L1 children $\left(\mathrm{F}_{1}(1,47)=3.88, \mathrm{p}=.055, \eta_{\mathrm{p}}{ }^{2}=.08 ; \mathrm{F}_{2}(1,14)=17.54, \mathrm{p}<.01, \eta_{\mathrm{p}}{ }^{2}=.56\right)$; the 


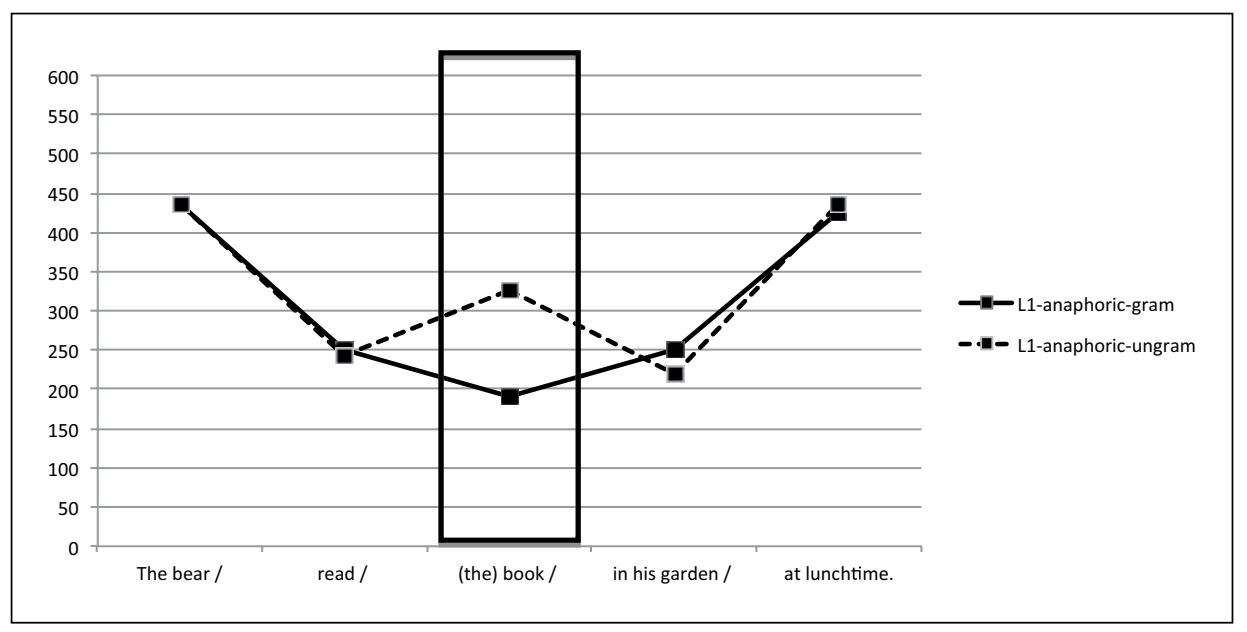

Figure 5. Mean residual RTs in ms for grammatical and ungrammatical sentences in the anaphoric condition for the English-speaking LI children.

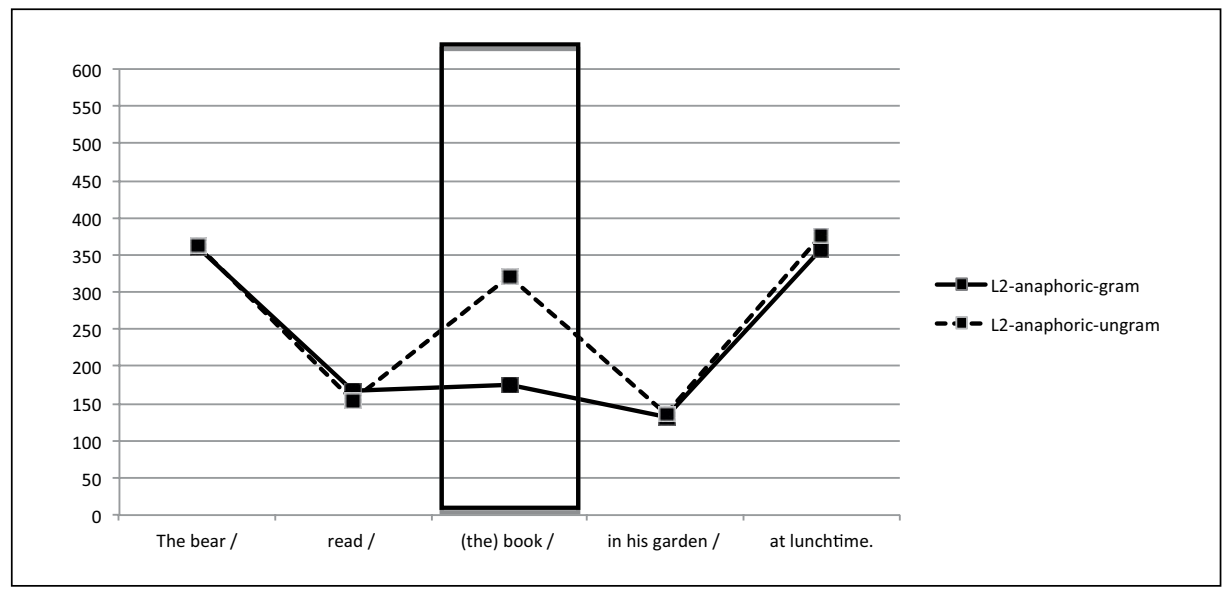

Figure 6. Mean residual RTs in ms for grammatical and ungrammatical sentences in the anaphoric condition for the English-speaking L2 children.

anaphoric condition elicited longer RTs than the bridging condition $\left(\mathrm{F}_{1}(1,47)=17, \mathrm{p}<\right.$ $\left..001, \eta_{\mathrm{p}}{ }^{2}=.26 ; \mathrm{F}_{2}(1,14)=6.54, \mathrm{p}<.05, \eta_{\mathrm{p}}^{2}=.32\right)$.

For the critical segment (Segment 3$)$, there was a main effect of Context $\left(\mathrm{F}_{1}(1,47)=\right.$ $\left.140.65, \mathrm{p}<.001, \eta_{\mathrm{p}}{ }^{2}=.750 ; \mathrm{F}_{2}(1,14)=12.84, \mathrm{p}<.01, \eta_{\mathrm{p}}{ }^{2}=.478\right)$, a main effect of Grammaticality $\left(\mathrm{F}_{1}(1,47)=217.545, \mathrm{p}<.001, \eta_{\mathrm{p}}{ }^{2}=.822 ; \mathrm{F}_{2}(1,14)=188.055, \mathrm{p}<.001\right.$, $\left.\eta_{\mathrm{p}}{ }^{2}=.931\right)$, an interaction between Grammaticality and Context in the per participant analysis $\left(\mathrm{F}_{1}(1,48)=11.05, \mathrm{p}<.01, \eta_{\mathrm{p}}{ }^{2}=.19 ; \mathrm{F}_{2}(1,14)=3.33, \mathrm{p}>.08, \eta_{\mathrm{p}}{ }^{2}=.192\right)$, and an 


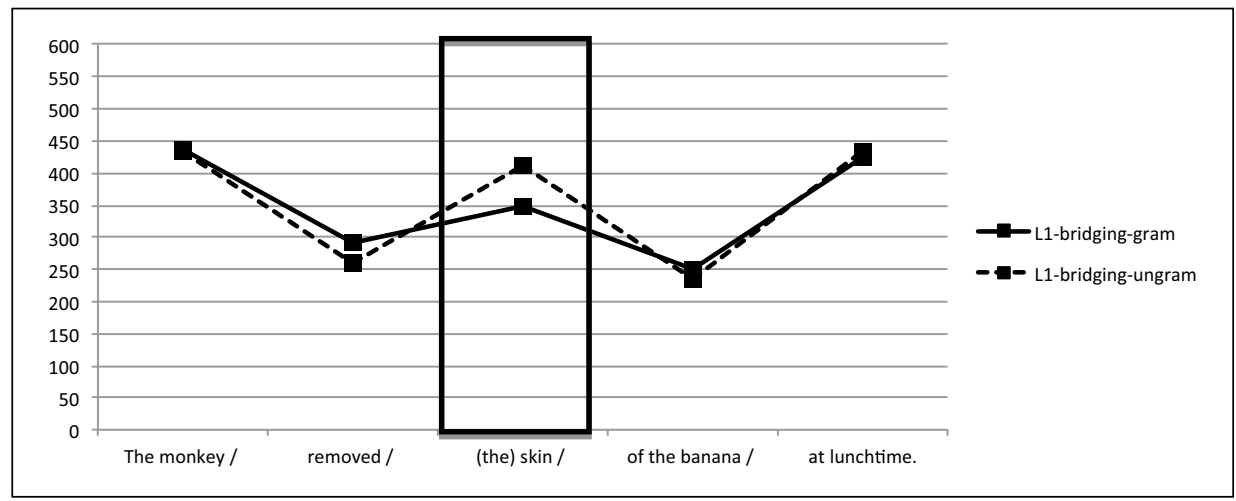

Figure 7. Mean residual RTs in ms for grammatical and ungrammatical sentences in the bridging condition for the English-speaking LI children.

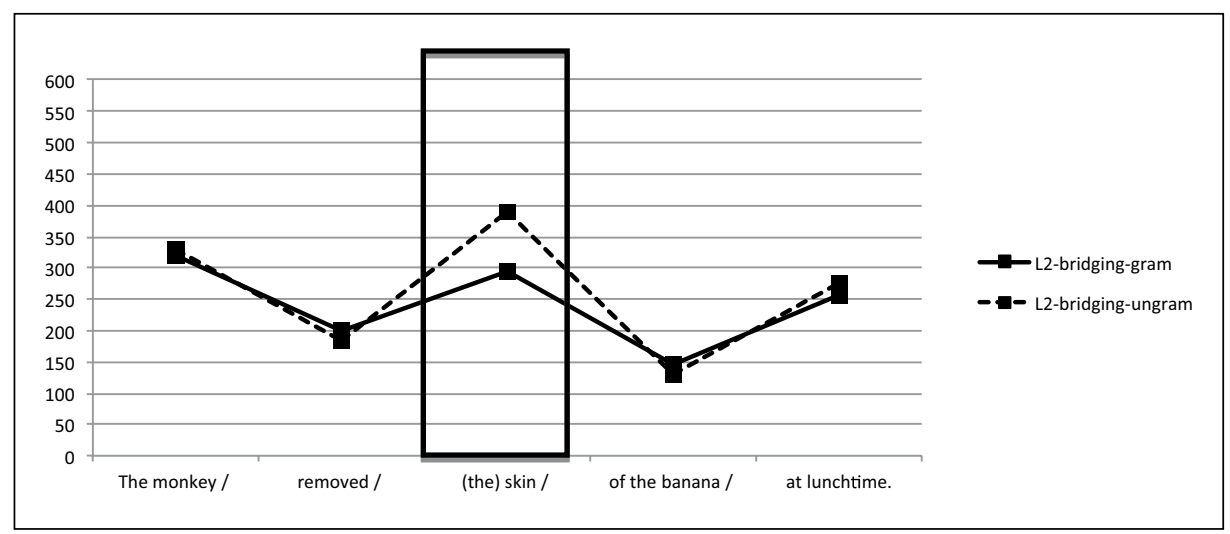

Figure 8. Mean residual RTs in ms for grammatical and ungrammatical sentences in the bridging condition for the English-speaking L2 children.

interaction between Grammaticality and Group in the per item analysis $\left(\mathrm{F}_{1}(1,48)=.283\right.$, $\left.\mathrm{p}>.5, \eta_{\mathrm{p}}^{2}=.006 ; \mathrm{F}_{2}(1,14)=9.71, \mathrm{p}<.01, \eta_{\mathrm{p}}^{2}=.41\right)$

Pairwise comparisons in the per participant analysis showed longer RTs in the ungrammatical vs. the grammatical condition for both the anaphoric $(\mathrm{t}(48)=-13.10, \mathrm{p}<.001)$ and bridging conditions $(\mathrm{t}(48)=-9.42, \mathrm{p}<.001)$ and longer RTs in the bridging compared to the anaphoric condition for both the grammatical $(\mathrm{t}(48)=-11.25, \mathrm{p}<.001)$ and ungrammatical conditions $(\mathrm{t}(48)=-7.06, \mathrm{p}<.001)$. The figures show that the difference between the grammatical and the ungrammatical conditions is more pronounced in the anaphoric than in the bridging condition. Further per item pairwise comparisons to unpack the Grammaticality by Group interaction revealed that both groups showed a significant effect of grammaticality $(\mathrm{L} 1: \mathrm{t}(15)=-4.91 . \mathrm{p}<.001 ; \mathrm{L} 2: \mathrm{t}(15)=-11.88, \mathrm{p}<$ $.001)$. The L2 children showed shorter RTs than the L1 children in the grammatical 
condition at the uncorrected alpha decision level of .05 , but this effect was not retained after a Bonferroni correction $(\mathrm{t}(30)=2.22, \mathrm{p}=.03)$. There was no difference between the two groups in the ungrammatical condition $(\mathrm{t}(30)=.87, \mathrm{p}=.39)$. In the post-critical segment (Segment 4), the L2 children had significantly shorter RTs than the L1 children $\left(\mathrm{F}_{1}(1,48)=9.20, \mathrm{p}<.01, \eta_{\mathrm{p}}{ }^{2}=.16 ; \mathrm{F}_{2}(1,14)=36.12, \mathrm{p}<.001, \eta_{\mathrm{p}}{ }^{2}=.72\right)$.

b Dutch study. Figures 9 to 12 show the residual RTs for the grammatical and the ungrammatical conditions for the definite article in the anaphoric and bridging contexts. For the pre-critical segment (Segment 2), the RTs were significantly longer in the anaphoric versus bridging condition in both groups $\left(\mathrm{F}_{1}(1,35)=193.92, \mathrm{p}<.001\right.$, $\left.\eta_{\mathrm{p}}{ }^{2}=.85 ; \mathrm{F}_{2}(1,14)=46.53, \mathrm{p}<.001, \eta_{\mathrm{p}}{ }^{2}=.77\right)$. A marginally significant interaction between Grammaticality and Group emerged in the per participant analysis $\left(\mathrm{F}_{1}(1,35)\right.$ $\left.=4.05, \mathrm{p}=.05, \eta_{\mathrm{p}} 2=.10\right)$. Inspection of the plots revealed that whereas the L1 children tended to listen longer to grammatical than to ungrammatical sentences $(t(19)=$ $2.01, \mathrm{p}=.06$, per participant), the (non-significant) pattern for L2 children was in the reverse direction.

For the critical segment (Segment 3), ungrammatical sentences elicited significantly longer RTs than grammatical sentences $\left(\mathrm{F}_{1}(1,35)=55.80, \mathrm{p}<.001, \eta_{\mathrm{p}}{ }^{2}=.62 ; \mathrm{F}_{2}(1,14)=\right.$ $\left.16.43, \mathrm{p}<.001, \eta_{\mathrm{p}}{ }^{2}=.54\right)$. We also found a significant interaction between Context and Grammaticality in the per participant analysis $\left(\mathrm{F}_{1}(1,35)=4.09, \mathrm{p}=.05, \eta_{\mathrm{p}} 2=.11\right)$. Paired samples t-tests reveal a difference between anaphoric and bridging context for grammatical $\mathrm{t}(36)=3.13, \mathrm{p}<.01$, per participant) but not for ungrammatical sentences $(\mathrm{t}(36)=$ $.41, \mathrm{p}=.97$, per participant).

For the segment following the critical segment (Segment 4), the RTs were longer in the anaphoric vs. bridging condition $\left(\mathrm{F}_{1}(1,35)=46.38, \mathrm{p}<.001, \eta_{\mathrm{p}}{ }^{2}=.47 ; \mathrm{F}_{2}(1,14)=\right.$ 5.39, $\mathrm{p}=.04, \eta_{\mathrm{p}}^{2}=.28$ ).

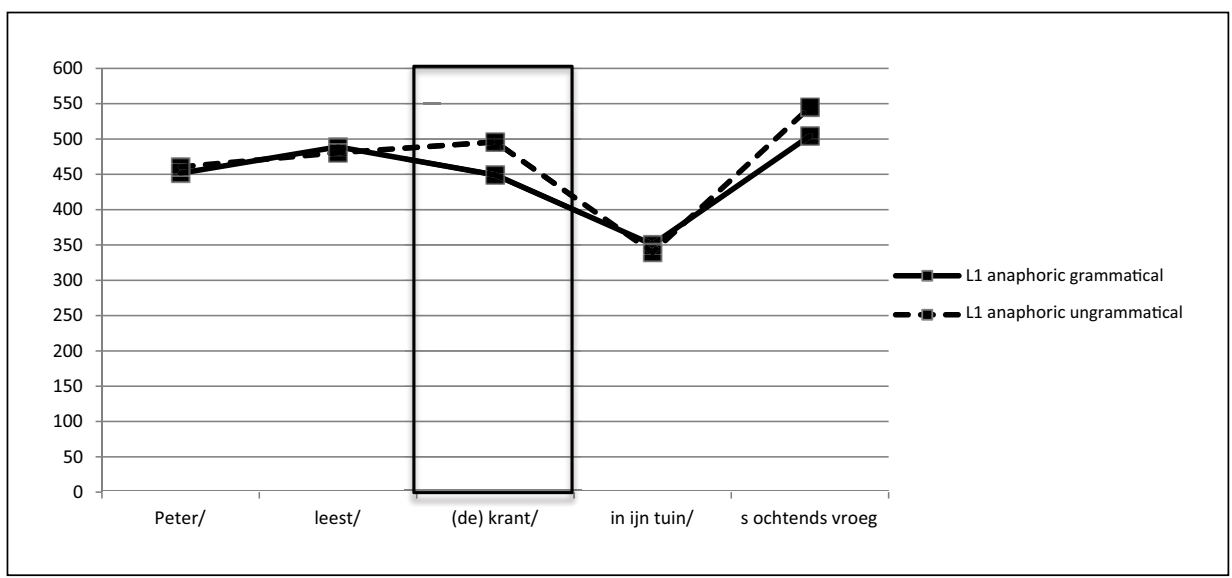

Figure 9. Mean residual RTs in ms grammatical and ungrammatical sentences in the anaphoric condition for the Dutch-speaking LI children. 


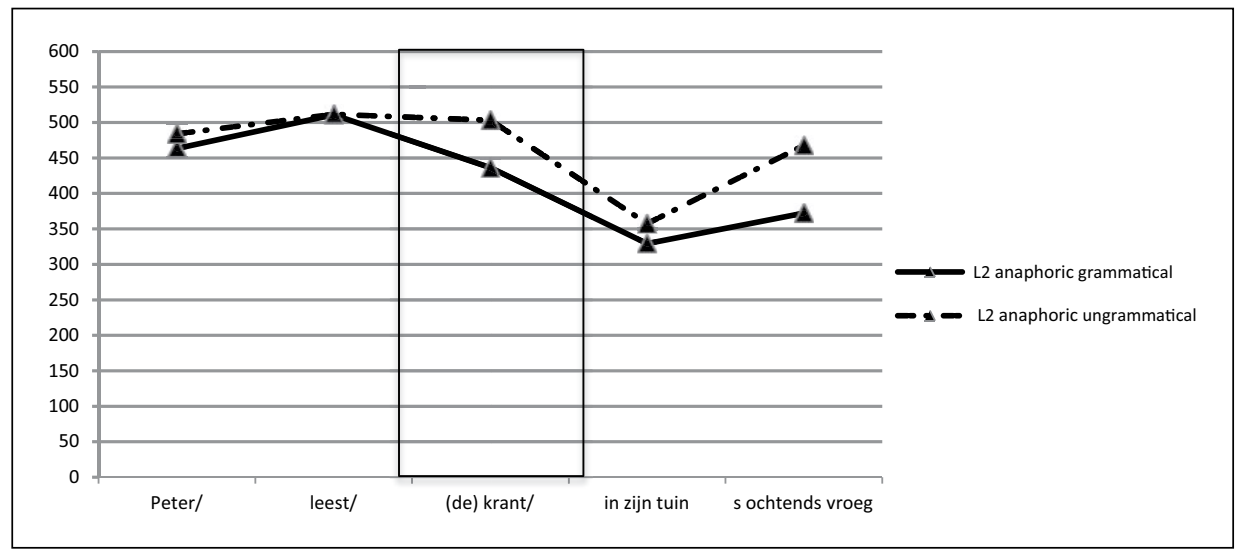

Figure 10. Mean residual RTs in ms grammatical and ungrammatical sentences in the anaphoric condition for the Dutch-speaking L2 children.

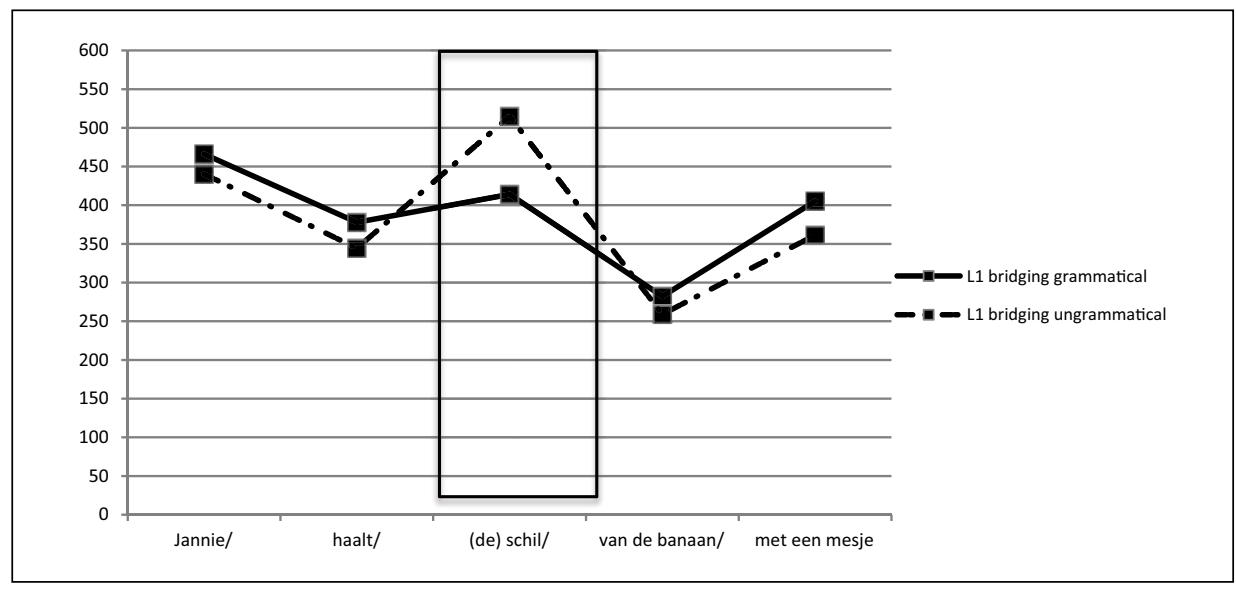

Figure I I. Mean residual RTs in ms grammatical and ungrammatical sentences in the bridging condition for the Dutch-speaking LI children.

\section{Production-processing (a)symmetries}

To examine whether children with high article omission rates in the production task were sensitive to the ungrammaticality induced by article omission in the on-line processing task, we split each language group into two further subgroups on the basis of their performance on the anaphoric and bridging condition in the production task. Children whose omission rate was $75 \%$ and above were classified as 'article-droppers', and children with an omission rate of less than $75 \%$ were categorized as 'non-article-droppers'. 8 


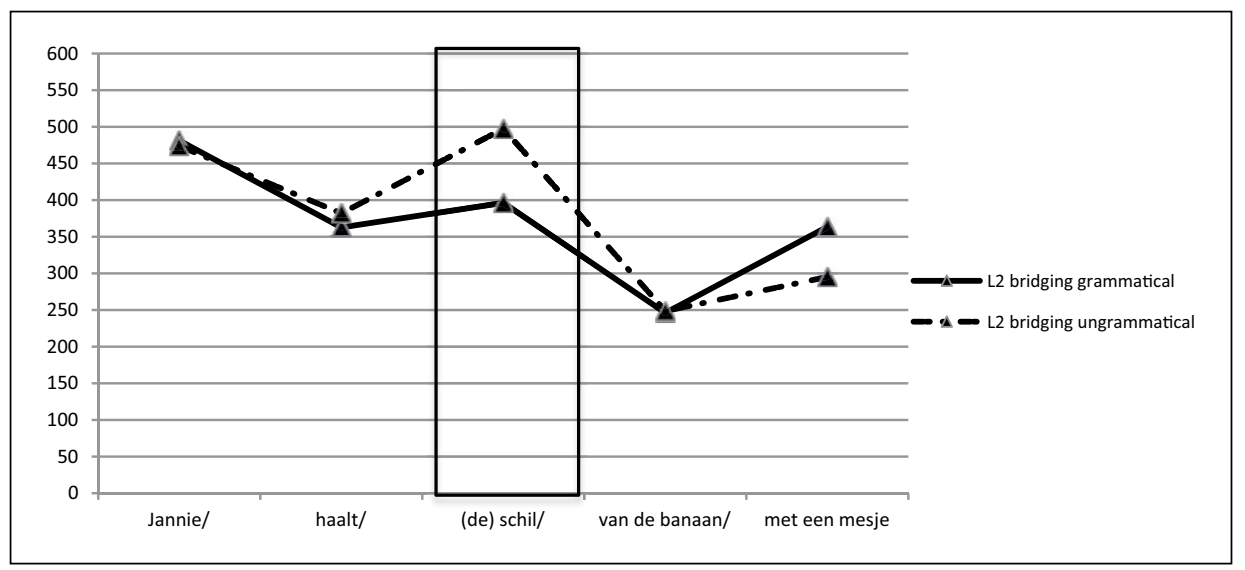

Figure 12. Mean residual RTs in ms grammatical and ungrammatical sentences in the bridging condition for the Dutch-speaking L2 children.

a English study. In the anaphoric condition, based on the $75 \%$ criterion the $\mathrm{L} 1$ and the L2 children were divided into four groups: (1) 4 L1 'article-droppers' (mean omission: 83.3\%), (2) 24 L1 'non-article-droppers' (mean omission: 19.4\%, range: 0\%66.7\%, SD: 26.3), (3) 9 L2 'article-droppers' (mean omission: 94.1\%, range: 80\%-100\%, SD: 8.9), and (4) 13 L2 'non-article-droppers' (mean omission: $28.5 \%$, range: $0 \%-66.7 \%$, SD: 26 ). To address production-processing (a)symmetries we calculated the mean residual RTs in the critical segment (Segment 3) for each of these four groups on the grammatical and ungrammatical condition in the on-line processing task, as shown in Table 2.

Given the low number of L1 children in the 'article-droppers' group statistical comparisons for the L1 children are not reliable and were therefore not run, although both droppers and non-droppers show longer RTs in the ungrammatical compared to the grammatical conditions. For the L2 children, a repeated-measures ANOVA with Grammaticality (grammatical, ungrammatical) as the within participants factor and Group (article-droppers, non-article-droppers) as the between participants factor revealed that the ungrammatical condition had significantly longer RTs than the grammatical condition $\left(\mathrm{F}_{1}(1,20)=101.97, \mathrm{p}<.001, \eta_{\mathrm{p}}{ }^{2}=.84 ; \mathrm{F}_{2}(1,14)=133.21, \mathrm{p}<.001, \eta_{\mathrm{p}}{ }^{2}=.91\right)$. There was no interaction between Grammaticality and Group, suggesting that both L2 groups were sensitive to the ungrammaticality.

In the bridging condition, the children were also divided into four groups based on the 75\% criterion: ${ }^{9}$ (1) 2 L1 'article-droppers' (mean omission: $91.7 \%$, range: $83.3 \%-100 \%$, SD: 11.8), (2) 26 L1 'non-article-droppers' (mean omission: 12.2\%, range: $0 \%-50 \%$, SD: 18.6), (3) 2 L2 'article-droppers' (mean omission: $91.7 \%$, range: $83.3 \%-100 \%$, SD: 11.8), and (4) 20 L2 'non-article-droppers' (mean omission: $14.5 \%$, range: $0 \%-66.7 \%$, SD: 19.8). To address production-processing (a)symmetries we calculated the mean residual RTs for each of these four groups on the grammatical and ungrammatical condition in the bridging context on the on-line processing task, as shown in Table 3. Because of the low number of L1 and L2 children in the 'article-droppers' group we did not run 
Table 2. Mean residual Reaction Times (RTs) in ms (SDs in brackets) in the critical segment for the grammatical and ungrammatical condition in the anaphoric context for the Englishspeaking LI and the L2 children.

\begin{tabular}{|c|c|c|c|c|}
\hline \multirow[t]{2}{*}{ Anaphoric context } & \multicolumn{2}{|l|}{ LI children } & \multicolumn{2}{|l|}{ L2 children } \\
\hline & $\begin{array}{l}\text { Article-droppers } \\
(n=4)\end{array}$ & $\begin{array}{l}\text { Non-droppers } \\
(n=24)\end{array}$ & $\begin{array}{l}\text { Article-droppers } \\
(n=9)\end{array}$ & $\begin{array}{l}\text { Non-droppers } \\
(n=13)\end{array}$ \\
\hline Grammatical & $365(163)$ & $163(89)$ & $209(125)$ & $152(103)$ \\
\hline Ungrammatical & $423(200)$ & $310(103)$ & $363(93)$ & $294(98)$ \\
\hline
\end{tabular}

Table 3. Mean residual Reaction Times (RTs) in ms (SD in brackets) in the critical segment for the grammatical and ungrammatical condition in the bridging context for the English-speaking $\mathrm{LI}$ and the L2 children.

\begin{tabular}{|c|c|c|c|c|}
\hline \multirow{2}{*}{$\begin{array}{l}\text { Bridging } \\
\text { context }\end{array}$} & \multicolumn{2}{|l|}{ LI children } & \multicolumn{2}{|l|}{ L2 children } \\
\hline & $\begin{array}{l}\text { Article-droppers } \\
(n=2)\end{array}$ & $\begin{array}{l}\text { Non-droppers } \\
(n=26)\end{array}$ & $\begin{array}{l}\text { Article-droppers } \\
(n=2)\end{array}$ & $\begin{array}{l}\text { Non-droppers } \\
(n=20)\end{array}$ \\
\hline Grammatical & $629(225)$ & $285(98)$ & 351 (169) & $289(102)$ \\
\hline Ungrammatical & $667(138)$ & $378(90)$ & 474 (I35) & $393(70)$ \\
\hline
\end{tabular}

Table 4. Mean residual Reaction Times (RTs) in ms (SD in brackets) in the critical segment for the grammatical and ungrammatical condition in the anaphoric context for the Dutch-speaking L2 children.

\begin{tabular}{lll}
\hline Anaphoric context & L2 children & \\
\cline { 2 - 3 } & Article-droppers $(n=5)$ & Non-droppers $(n=12)$ \\
\hline Grammatical & $413(101)$ & $446(103)$ \\
Ungrammatical & $506(57)$ & $502(119)$ \\
\hline
\end{tabular}

any statistical comparisons, but both droppers and non-droppers show longer RTs in the ungrammatical compared to the grammatical conditions.

b Dutch study. In the Dutch study, there were no L1 'article-droppers' in either of the two semantic conditions. Therefore, only the L2 children were divided in the two groups of 'article-droppers' and 'non-article-droppers'. More specifically, there were two L2 groups in the anaphoric condition: (1) L2 'article-droppers' (5 children; mean omission rate: $97.2 \%$; range: $86 \%-100 \%$, SD: 6.2), and (2) L2 'non-article-droppers (12 children; mean omission rate: $17.6 \%$; range: $0 \%-60 \%$, SD: 16.7 ). Table 4 shows the mean residual RTs for the two L2 groups. The analysis showed that the ungrammatical condition elicited longer RTs than the grammatical one $\left(\mathrm{F}_{1}(1,15)=12.54, \mathrm{p}<.01, \eta_{\mathrm{p}}{ }^{2}=.46 ; \mathrm{F}_{2}(1,14)\right.$ $=4.07, \mathrm{p}=.06$ (tendency), $\eta_{\mathrm{p}}^{2}=.23$ ). No further interactions emerged between Grammaticality and Group. 
Table 5. Mean residual Reaction Times (RTs) in ms (SD in brackets) in the critical segment for the grammatical and ungrammatical condition in the bridging context for the Dutch-speaking L2 children.

\begin{tabular}{lll}
\hline Bridging context & \multicolumn{2}{l}{ L2 children } \\
\cline { 2 - 3 } & Article-droppers $(n=6)$ & Non-droppers $(n=10)$ \\
\hline Grammatical & $390(105)$ & $414(87)$ \\
Ungrammatical & $470(101)$ & $518(102)$ \\
\hline
\end{tabular}

For the bridging condition the children were also assigned to two groups: (1) L2 'article-droppers' (6 children; a mean omission rate: $97.6 \%$; range: $86 \%-100 \%$, SD: 5.7), and (3) L2 'non-article-droppers' (10 children; mean omission rate: $8.8 \%$; range: 0\%-29\%, SD: 12.3$).{ }^{10}$ See Table 5.

In the bridging condition one item was removed from the analysis because its grammatical version was the first experimental item that all children were presented with in the experiment and reacted to with unusually long reaction times in the pre-critical region (164 ms longer than in the ungrammatical sentence to the identical segment) in the L2 subgroup that frequently dropped articles. We removed this item from the analysis of both groups. ${ }^{11}$ The analysis revealed again only a main effect of Grammaticality $\left(\mathrm{F}_{1}(1,14)\right.$ $\left.=18.73, \mathrm{p}<.001, \eta_{\mathrm{p}}^{2}=.57 ; \mathrm{F}_{2}(1,12)=7.87, \mathrm{p}=.02, \eta_{\mathrm{p}}^{2}=.40\right)$.

\section{Discussion}

This study examined how Turkish-speaking children learning English and Dutch as second languages in the UK and in the Netherlands respectively, and L1 English and Dutch age-matched control children acquire definite noun phrases in the object position in two semantic contexts, anaphoric and bridging. Turkish expresses definiteness in both contexts through accusative case. From a learnability perspective, for the Turkish children to acquire definite articles in English and Dutch and develop abstract grammatical representations, they have to select and reassemble the definiteness feature from the Turkish accusative case and map it into the English and Dutch definite articles. To address whether or not the L2 children have an abstract grammatical representation, we used two tasks, an elicitation task tapping how children produce definite articles and an on-line comprehension task tapping whether children are sensitive to the omission of definite articles when they listen to sentences in real-time.

Overall, the production data revealed that in both English and Dutch the L2 children and the $\mathrm{L} 1$ controls were more accurate in producing definite articles in the bridging than in the anaphoric condition and the predominant error was definite article drop. The online comprehension data revealed that in both languages the L2 children and L1 controls showed longer RTs when there was an ungrammaticality caused by definite article drop compared to grammatical sentences in both the anaphoric and the bridging condition. This demonstrates that children were sensitive to the omission of definite articles when they were processing the sentences in real-time. Importantly, sensitivity to article drop was also evident in the subgroups of children who had high rates of article drop in 
production. This pattern demonstrates an asymmetry between the children's production and on-line comprehension. The effects of context and the asymmetry between production and comprehension will be discussed in detail in the following subsections.

\section{Effects of semantic context: Differences between the anaphoric vs. the bridging condition}

The first research question addressed whether or not the L2 children and the L1 controls are affected by the semantic context of definite articles (anaphoric and bridging). Previous studies on L1 children comparing the production of definite articles in these two conditions showed that pre-school children were less accurate in the anaphoric than in the bridging condition (Schafer and de Villiers, 2000). Moreover, the predominant error type was omission of definite articles. Our findings with older L1 and L2 children are in line with the results by Schafer and de Villiers. All groups of children in our study were less accurate in using definite articles in the anaphoric than in the bridging context.

Schafer and de Villiers (2000) attributed the lower performance in the anaphoric condition to problems with taking the hearer's perspective as exhibited by the young children in their study. The children in both studies reported here were older than the children in Schafer and de Villiers, and therefore, difficulties in the anaphoric condition cannot be attributed to perspective taking. We believe that the discrepancy between the two contexts can be attributed to the way definiteness is established in the two conditions, i.e. via discourse reference vs. via direct mapping due to part-whole entailment and world knowledge. In the anaphoric condition, an entity is introduced into the discourse through an indefinite expression; subsequently, a definite expression is used to refer to the entity that is already in the discourse. In our production experiments, two entities were introduced into the discourse by the experimenter using an indefinite expression; then, the child had to refer to one of the two entities using a definite expression. To do that, the child had to keep track of the referents introduced into the discourse by the experimenter, store them in working memory, acknowledge that they are known to the hearer (experimenter) and maintain discourse continuity by referring to one of them using the definite article. Consequently, the anaphoric use of the definite article presupposes understanding that the information originally known only to the speaker is now shared by the hearer and the speaker, and thus, a definite expression is required. This requires manipulating indefinite and definite article use. In the bridging condition, on the other hand, there are no requirements to maintain discourse reference. If children know the target noun in the part-whole relationship, e.g. that bananas have skin, and they also have acquired that uniqueness and definiteness in English are mapped onto the definite article 'the', then definite article use comes for free. Importantly, this bridging use of definite articles or first mention definites has been shown to be acquired early (Avrutin and Coopmans, 2000). The lower accuracy of all groups of L2 and L1 school-aged children in our study in the anaphoric compared with the bridging condition indicates that maintaining discourse reference is more difficult than establishing definiteness via direct reference through world knowledge.

The difference between the two conditions was also evident in the English on-line comprehension task. RTs for the definite expression in the anaphoric condition were shorter than in the bridging condition. This could be attributed to activation of the noun 
in the anaphoric but not the bridging condition. In the anaphoric condition, a noun was introduced using an indefinite expression in the leading sentence; the experimental sentence included the same noun in a definite expression or as a bare noun. That is, when children listened to the experimental sentence and their RTs were recorded, the noun was already activated in their mental lexicon. In the bridging condition, on the other hand, two different nouns were used in the leading sentence and the experimental sentence; these two nouns established a part-whole relationship. The noun in the experimental condition was not activated in the children's mental lexicon. Although this effect was only attested in the English task, we believe that the difference in RTs between the two conditions can be attributed to the activation of the noun during the leading sentence in the anaphoric condition.

\section{On-line processing of ungrammaticality: Evidence for underlying representation}

The second research question addressed the issue of whether or not children who omit definite articles in production are sensitive to the grammatical violations induced by definite article omission in an on-line comprehension task. Previous studies using online comprehension tasks have shown that L2 learners are sensitive to some types of grammatical violations when they process sentences on-line (e.g. to tense Chondrogianni and Marinis, 2012 or gender violations Blom and Vasić, 2011), but this depends on the structure tested and the level of proficiency, especially in the case of adult L2 learners (VanPatten et al., 2012).

Our results revealed that all groups of L 2 children and L1 controls showed longer RTs when the definite article was omitted compared to sentences with definite articles in both semantic contexts. This indicates that they were sensitive to the ungrammaticality induced by article omission. To address the relationship between article drop in production and sensitivity to omission in on-line comprehension, we divided the groups of children into article-droppers and non-article-droppers based on the criterion of $75 \%$ drop of definite articles. Both article-droppers and non-article-droppers were sensitive to the omission of definite articles in the on-line comprehension task. This suggests that children subconsciously detect the ungrammaticality of definite article drop even though they omit definite articles in their production.

One of the key questions in L2 acquisition research is whether or not L2 learners have abstract syntactic representations. Studies on child L2 acquisition have mostly provided evidence that L2 children have abstract syntactic representations despite errors of omission of grammatical morphemes (e.g., Chondrogianni and Marinis, 2012; Haznedar and Schwartz, 1997; Ionin and Wexler, 2002; Paradis et al., 2008; Prévost and White, 2000), arguing in favour of the MSIH (Haznedar and Schwartz, 1997). This raises the question of why L2 children omit grammatical morphemes if they have intact abstract syntactic representations. In the present study, this amounts to asking why they omit definite articles if they have selected and reassembled the definiteness feature from their L1 and mapped it onto definite articles in their L2. ${ }^{12}$

Comprehension and production are two different modalities that, apart from the motor processes involved in articulation, follow the same processes but in a different order. In 
comprehension, participants listen to sentences, they have to segment words and grammatical morphemes from the incoming stream, access the mental lexicon and build abstract syntactic representations based on the words and grammatical morphemes they identify. In terms of our on-line comprehension experiments on definiteness, the leading sentence causes activation of the words in the mental lexicon and the nouns of the leading sentence become part of the participants' discourse representation. By encountering the experimental sentence, a definite noun phrase activates the [+definite] feature which matches the definiteness of the noun in the discourse representation. When the experimental sentence has a bare noun, the [+definite] feature will not be activated. As a result, there will be a mismatch between the discourse representation of the noun and the definiteness of the bare noun; this mismatch can result in elevated RTs. By the same rationale, a lack of elevated RTs would provide evidence that the learners have not mapped the $[+$ definite $]$ feature to the definite article. ${ }^{13}$

In production, on the other hand, participants start with a message they want to convey, they build the abstract syntactic representation and then access the mental lexicon to select and insert the grammatical morphemes into the abstract syntactic representation. This is followed by a final step, unique to speech production, which is the articulation. In terms of our production tasks on definiteness, participants listen to a short story. The nouns in the story are activated in the mental lexicon and become part of the participants' discourse representation. When they produce the target sentence with a definite expression, this involves building up an abstract syntactic representation with a [ + definite] DP. Next, they access and retrieve the noun and the definite article from the mental lexicon and, finally, they use the articulator to produce the phrase/sentence. In production, omission of the definite article does not necessarily provide evidence for a lack of the $[+$ definite] feature and inability to build up the syntactic representation. It may indicate difficulties in accessing and retrieving the definite article from the mental lexicon, or L2 learners may fail to articulate the definite article because of prosodic reasons, because of lack of automaticity or a combination of those factors (Goad and White, 2006; VanPatten et al., 2012; White, 2003).

Within a separation view of the lexicon (Halle and Marantz, 1993) adopted in the present article, lexical and inflectional information is stored under different entries. Lexical information associated with nouns is related to conceptual and world knowledge information, and for that reason, may be considered more primitive than inflectional information, which is subject to parameterization and learnability constraints. In this sense, retrieving and spelling out the noun is more important in terms of informational content and presumably easier to access given its direct denotation of world entities than inflection. This contrasts with the processes involved in the on-line comprehension task, where the noun is already given in the sentence. In this case, the task of the L2 comprehender is to compute the syntactic and semantic relationships between already given lexical items. Given that the lexical items are already provided, this may enable them to detect the ungrammaticality induced by article omission.

Another possible reason may be that L2 learners fail to articulate the definite article because of prosodic reasons, as the PTH would suggest (Goad and White, 2006). In Turkish, the morpho-syntactic element that encodes definiteness is an inflectional element (accusative case) of an affixal nature (suffix); this suffix is a strong syllable and 
forms part of the prosodic structure of the word. In English and Dutch, on the other hand, the morpho-syntactic element that encodes the same information is a phonologically weak, proclitic element that forms part of the phonological phrase with which it prosodifies. It is therefore possible that the differences in prosodification between the three languages (Goad and White, 2004), as well as the occurrence of the definiteness feature within different levels of prosodification (phonological word vs. phonological phrase) give rise to articulation or spell-out problems. However, the PTH alone cannot explain why L 2 children perform better on the bridging compared with the anaphoric use of definite articles, given that the prosodic properties of the definite articles in both semantic contexts remained the same.

Finally, previous studies have shown that word retrieval and articulation is less automatic in non-advanced L2 learners compared with L1 speakers (Segalowitz and Hulstijn, 2005) and that lexical access may be modulated by vocabulary size (Bialystok et al., 2008). The L 2 children in our study had smaller vocabularies than the L1 children, and this factor may have affected performance on the production task. However, low vocabulary abilities alone do not explain why articles are omitted more than nouns.

In the present study it is not possible to pinpoint which one of the above-mentioned factors (lexical retrieval problems, prosodic transfer effects, prosodic reasons, or lack of automaticity) caused the omission errors in production because we only used a single production task that cannot separate these processes. Future studies using separate tasks that investigate each one of these factors individually could highlight why children omit at all in view of intact syntactic representations.

Finally, there are various limitations of the present study that future research would benefit from addressing. Firstly, in the present study we only investigated the production and on-line comprehension of definite articles but not of indefinite articles. Given the current extended research on indefinite articles (e.g. Ionin et al., 2004, 2009), future research would benefit greatly from investigating the status of indefinite articles in production and on-line processing, their interplay with definite articles, and how production and on-line processing of indefinite articles is influenced by L1 properties. ${ }^{14}$

Additionally, in the present study we investigated definite articles in the object position only. To understand fully the status of the L2 articles in the children's interlanguage, one would need to test article production in both the subject and the object position, given that subjects in Turkish are not case-marked whereas objects are.

Finally, given that definiteness is realized cross-linguistically via different linguistic means, e.g. word order and scrambling vs. free or bound morphemes, future research would benefit from investigating different L1-L2 combinations, so as to fully understand how L1 and L2 properties interact in the context of the acquisition of definiteness.

\section{Conclusions}

This study examined production and on-line comprehension of definite articles in schoolaged L1-Turkish L2-English and L1-Turkish L2-Dutch children, and in L1-English and L1-Dutch age-matched controls. Definiteness was established either via linguistic means during discourse maintenance (anaphoric context) or via world knowledge (bridging 
context). All groups of children were less accurate in the anaphoric compared to the bridging context, indicating that keeping track of the discourse referents is more costly than establishing definiteness via world knowledge. All groups of children across the two studies were also sensitive to definite article omission in the on-line comprehension task. This suggests that the errors of omission are not due to the lack of abstract syntactic representations, but are more likely to result from prosodic reasons, difficulties in lexical access and retrieval of definite articles from the mental lexicon, difficulties with articulatory planning and automatization or a combination of these factors. This is in line with previous findings in child L2 production and on-line comprehension and provides support for the idea that missing grammatical morphemes in L2 children's speech can go hand-in-hand with grammatical knowledge.

\section{Declaration of conflicting interest}

The authors declare that there is no conflict of interest.

\section{Funding}

This project was funded by the Dutch Research Organisation (NW0) Dutch project number: 25470-120, UK project number: 254-70-121).

\section{Notes}

1. Definite NPs are also specific, that is, the speaker refers to a unique entity in the set denoted by the NP, and considers this entity to possess a noteworthy property (Ionin et al., 2004). In English and Dutch, indefinite articles can be [-definite], [+specific], as the noun phrase $a$ cat / een kat in example (1), or [-definite,--specific], as the noun phrase a banana in example (2). In the present article, we only focus on definite articles.

2. The 3-year-olds were at chance level in rejecting ungrammatical sentences in both Dutch and Russian. This was interpreted to reflect lack of processing resources required to reject these computations (Avrutin and Coopmans, 2000).

3. One reviewer raises the question whether for the L2 children in the present study the L1 features were already in place in the children's L1, so that one can talk about feature re-assembly. The contexts we examined involved the use of simple definite articles in the object position. The counterpart of this construction in Turkish would be accusative case-marked nouns. Accusative case marking and its interaction with definiteness and argumenthood is acquired early (approximately by the age of four years) in typically developing L1 Turkish-speaking children (Ketrez, 2005). Therefore, we assume that the features addressed in the present study were already in place in the children's L1. In the present study, we did not investigate late acquired structures in Turkish, such as the interaction between indefinite noun phrases and scope ambiguities.

4. Note that bir in its indefinite use is unstressed, whereas bir in its use as a numeral is stressed, in which case it can attach at the PPh level.

5. Goad and White (2004) propose two other options: the Turkish L2 learner of English treats articles (i) as word internal syllables, or (ii) as stressed pronouns or numerals on a par with the stressed Turkish numeral bir. To test (i) we would have needed to have nouns that do not bear word initial stress. In the present study all nouns in both semantic contexts were monosyllabic or bore word initial stress in both English and Dutch. We did not attest any instances of stressed definite articles in any of the two studies reported here. 
6. We focused on nouns in the object position because this is the context where nouns are casemarked in Turkish, and, therefore, there is an overt definiteness/specificity marker also in the L1.

7. In a previous study on Dutch articles, van Hout et al. (2010) mention that in their task, which used a question to elicit a response, some children tended to omit articles across the board. By adapting this method and attempting to elicit a prepositional phrase, we hoped to avoid such task effects.

8. We chose the $75 \%$ cut-off point after using visual binning in SPSS to explore the data and look for natural cut-off points in the two data sets. The $75 \%$ emerged as a natural cut-off point in both data sets, which means that the L 2 children omitted in 5 out of 6 contexts.

9. The four groups in the anaphoric condition were not the same in the bridging condition.

10. One child was removed from the analysis of the processing data of the bridging condition; she could not be classified on the basis of accuracy in production because of missing data in this particular condition.

11. The item in question was kept in the rest of the analysis because its removal did not change the results.

12. As one reviewer points out, and we agree, it is difficult to disentangle the MSIH from the feature (re-)assembly hypothesis. As White (2009) observes, the feature (re-)assembly and the MSIH are conceptually very closely related, as they both hypothesize that lack of overt morphology does not presuppose lack of underlying grammatical representations. However, the MSIH does not take the nature of the morpo-phonological or semantic properties of the L2 system into account, whereas the feature (re-)assembly does to a certain extent. In the present study, both theories can account for the production-processing asymmetry. However, the feature (re-)assembly, in contrast to the MSIH, can accommodate the nature of the semantic properties of the L2 input. Therefore, it can to an extent accommodate the difference between the two definite conditions, as feature re-assembly would also include semantic features.

13. A lack of elevated RTs could also be caused by other factors, such as weak lexical representations or difficulties in maintaining the discourse representation possibly due to working memory limitations. These possibilities will not be discussed further because the participants in our study showed elevated RTs in the mismatch conditions.

14. In a recent study (Chondrogianni and Marinis, under review), we showed that the same L1-Turkish L2-English children reported in the present study do not fluctuate in their indefinite article use in specific contexts, as it has been previously reported (Ionin et al., 2009; Zdorenko and Paradis, 2008). This difference may be both task- and L1-related.

\section{References}

Avrutin S and Coopmans P (2000) Children who build bridges. In: Howell SC and Fish SH (eds) Proceedings of the Boston University Conference on Language Development (BUCLD) 24. Somerville, MA: Cascadilla Press, 80-91.

Bialystok E, Craik FIM, and Luk G (2008) Lexical access in bilinguals: Effects of vocabulary size and executive control. Journal of Neurolinguistics 21: 522-38.

Bishop DVM (2003) Test for Reception of Grammar: Version 2 (TROG-2). London: The Psychological Corporation.

Blom E and Vasić N (2011) The production and processing of determiner-noun agreement in child L2 Dutch. Linguistic Approaches to Bilingualism 1: 265-90.

Blom E, Polišenská D, and Weerman F (2008) Determiners, adjectives and age of onset: The acquisition of Dutch grammatical gender. Second Language Research 24: 289-323.

Brown R (1973) A First Language: The Early Stages. London: Penguin Books. 
Chomsky N (1993) A minimalist program for linguistic theory. In: Hale K and Keyser SJ (eds) The View From Building 20. Cambridge, MA: MIT Press, 1-52.

Chondrogianni V (2008) Comparing child and adult L2 acquisition of the Greek DP: Effects of age and construction. In: Haznedar B and Gavruseva E (eds) Current Trends in Child Second Language Acquisition. Amsterdam: John Benjamin, 97-142.

Chondrogianni V and Marinis T (2011) Differential effects of internal and external factors on the development of vocabulary, morphology and complex syntax in successive bilingual children. Linguistic Approaches to Bilingualism 1: 223-48.

Chondrogianni V and Marinis T (2012) Production and processing asymmetries in the acquisition of tense morphology by sequential bilingual children. Bilingualism: Language and Cognition 12: 1-19.

Chondrogianni V and Marinis T (under review) L2 children do not fluctuate: Production and online processing of indefinite articles in Turkish-speaking child L2 learners of English.

Clahsen H (2008) Behavioral methods for investigating morphological and syntactic processing in children. In: Sekerina IA, Fernández EM, and Clahsen H (eds) Developmental Psycholinguistics: On-line Methods in Children's Language Processing. Amsterdam: John Benjamins, 1-27.

Cornips L and Hulk A (2008) Factors of success and failure in the acquisition of grammatical gender in Dutch. Second Language Research 24: 267-95.

Damhuis R, de Glopper K, Boers M, and Kienstra M (1992) Wordenlijst voor 4- tot 6-jarigen: Een streeflijst voor kleuters. Rotterdam: CED Groep - Het Projectbureau OVB.

Dunn LM, Dunn LM, Whetton C, and Burley J (1997). The British Picture Vocabulary Scale. 2nd edition. Windsor: NFER-Nelson.

Enç M (1991) The semantics of specificity. Linguistic Inquiry 22: 1-25.

Goad H and White L (2004) Ultimate attainment of L2 inflection: Effects of L1 prosodic structure. In: Foster-Cohen S, Sharwood Smith M, Sorace A, and Ota M (eds) EUROSLA Yearbook 4. Amsterdam: John Benjamins, 119-45.

Goad H and White L (2006) Ultimate attainment in interlanguage grammars: A prosodic approach. Second Language Research 22: 243-68.

Göksel A and Kerslake C (2005) Turkish: A Comprehensive Grammar. London: Routledge.

Granfeldt J and Schlyter S (2004) Cliticization in the acquisition of French as L1 and L2. In: Prevost P (ed.) Acquisition of French in Different Contexts: Focus on Functional Categories. Amsterdam: John Benjamins, 333-70.

Grüter T (2005) Comprehension and production of French object clitics by child second language learners and children with specific language impairment. Applied Psycholinguistics 26: 363 91.

Grüter T, Lew-Williams C, and Fernald A (2012) Grammatical gender in the L2: A production or on-line processing problem? Second Language Research 28: 191-215.

Guasti MT, Gavarrò A, Lange J, and Caprin C (2008) Article omission across child language. Language Acquisition 15: 89-119.

Halle M and Marantz A (1993) Distributed morphology and the pieces of inflection. In: Hale K and Keyser SJ (eds) The View from Building 20. Cambridge MA: MIT Press, 111-76.

Hawkins JA (1991) On (in)definite articles: Implicatures and (un)grammaticality prediction. Journal of Linguistics 27: 405-42.

Hawkins R and Chan CY (1997) The partial availability of universal grammar in second language acquisition: The 'failed functional features hypothesis'. Second Language Research 13: 187-226.

Haznedar B and Schwartz BD (1997) Are there optional infinitives in child L2 acquisition? In: Hughes E, Hughes M, and Greenhill A (eds) Proceedings of the 21st Boston University 
Conference on Language Development (BUCLD 21). Somerville, MA: Cascadilla Press, 257-68.

Heim I (1991) Articles and definiteness. In: von Stechow A and Wunderlich D (eds) Semantics: An International Handbook of Contemporary Research. Berlin: De Gruyter, 1-59.

Ionin T and Wexler K (2002) Why is 'is' easier than '-s'?: Acquisition of tense/agreement morphology by child second language learners of English. Second Language Research 18: 95-136.

Ionin T, Ko H, and Wexler K (2004) Article semantics in L2 acquisition: The role of specificity. Language Acquisition 12: 3-69.

Ionin T, Zubizaretta M, and Philippov V (2009) Acquisition of article semantics by child and adult L2-English learners. Bilingualism: Language and Cognition 12: 337-61.

Ketrez N (2005) Children's scope of indefinite objects. Unpublished PhD dissertation, UCLA, CA, USA.

Kornfilt J (1997) Turkish. London: Routledge.

Kupisch T (2004) On the relation between input frequency and acquisition patterns from a crosslinguistic perspective. In: van Kampen J and Baauw S (eds) Proceedings of GALA 2003. Utrecht: LOT Occasional Series, 199-210.

Kupisch T and Pierantozzi C (2010) Interpreting Definite Plural Subjects: A Comparison of German and Italian Monolingual and Bilingual Children. In: Franich K, Iserman KM, and Keil LL (eds) Proceedings of the 34th Boston University Conference of Language Development (BUCLD 34). Somerville, MA: Cascadilla Press, 245-54.

Lakshmanan U and Selinker L (1994) The status of CP and the tensed complementizer that in the developing L2 grammars of English. Second Language Research 10: 25-68.

Lardiere D (1998a) Case and tense in the 'fossilized' steady state. Second Language Research 14: $1-26$.

Lardiere D (1998b) Dissociating syntax from morphology in a divergent L2 end-state grammar. Second Language Research 14: 359-75.

Lardiere D (2005) On morphological Competence. In: Dekydtspotter L, Sprouse RA, and Liljestrand A (eds) Proceedings of the 7th Generative Approaches to Second Language Acquisition conference (GASLA 2004). Somerville MA: Cascadilla Press, 178-92.

Lardiere D (2009) Some thoughts on the contrastive analysis of features in second language acquisition. Second Language Research 25: 173-227.

Levelt WJM (1989) Speaking: From Intention to Articulation. Cambridge, MA: MIT Press.

Lyons C (1999) Definiteness. Cambridge: Cambridge University Press.

Maratsos M (1976) The Use of Definite and Indefinite Reference in Young Children. Cambridge: Cambridge University Press.

Marinis T (2010) Using on-line processing methods in language acquisition research. In: Blom E and Unsworth S (eds) Experimental Methods in Language Acquisition Research. Amsterdam: John Benjamins, 139-62.

Montrul S, Foote R, and Perpinán S (2008) Gender agreement in adult second language learners and Spanish heritage speakers: The effects of age and context of acquisition. Language Learning, 58: 503-53.

MRC Psycholinguistic Database (1997) Oxford: Medical Research Council.

Nespor M and Vogel I (1986) Prosodic Phonology. Dordrecht: Foris Publications.

Paradis J, Rice ML, Crago M, and Marquis J (2008) The acquisition of tense in English: Distinguishing child second language from first language and specific language impairment. Applied Psycholinguistics 29: 689-722.

Prévost P and White L (2000) Missing surface inflection or impairment in second language acquisition? Evidence from tense and agreement. Second Language Research 16: 103-33. 
Rozendaal M (2008) The acquisition of reference: A cross linguistic study. Unpublished doctoral dissertation, University of Amsterdam (LOT Series), Amsterdam, the Netherlands.

Schaeffer J and Matthewson L (2005) Grammar and pragmatics in the acquisition of article systems. Natural Language and Linguistic Theory 23: 53-101.

Schafer R and de Villiers J (2000) Imagining articles: What a and the can tell us about the emergence of the DP. In: Howell SC, Fish SH, and Keith-Lucas T (eds) Proceedings of the 24 Boston University Conference on Language Development (BUCLD 24). Somerville, MA: Cascadilla Press, 609-20.

Schlichting L and Lutje Spelberg H (2002) Lexilijst NL. Amsterdam: Pearson Assessment and Information BV.

Segalowitz N and Hulstijn J (2005) Automaticity in bilingualism and second language learning. In: Kroll J and de Groot AMB (eds) Handbook of Bilingualism: Psycholinguistic Approaches. Oxford: Oxford University Press, 371-88.

Selkirk E (1986) On derived domains in sentence phonology. Phonology Yearbook 3: 371-405.

Serratrice L, Sorace A, Filiaci F, and Baldo M (2011) Pronominal objects in English-Italian and Spanish-Italian bilingual children. Applied Psycholinguistics 33: 725-51.

Seymour H, Roeper T, de Villiers J, and de Villiers P (2005) Diagnostic Evaluation of Language Variation (DELV ${ }^{\mathrm{TM}}$ ): Norm-Referenced. San Antonio, TX: Harcourt Assessment.

Sorace A, Serratrice L, Filiaci F, and Baldo M (2009) Discourse conditions on subject pronoun realisation: Testing the linguistic intuitions of older bilingual children. Lingua 119: 460-77.

van Hout A, de Ree L, and de Ree M (2008) Dutch children's interpretation of definites and indefinites in discourse. In: Gavarrò A and Freitas MJ (eds) Proceedings of GALA 2007. Newcastle upon Tyne: Cambridge Scholars Publishing, 279-89.

van Hout A, Harrigan K, and de Villiers J (2010) Asymmetries in the acquisition of definite and indefinite NPs. Lingua 20: 1973-90.

VanPatten B, Keathing G, and Leeser M (2012) Missing verbal inflections as a representational problem. Linguistic Approaches to Bilingualism 2: 109-40.

Vasić N and Blom E (2011) Production and processing of determiners in Turkish-Dutch child L2 learners. In: Danis N, Mesh K, and Sung H (eds) Proceedings of the 35th Boston University Conference on Language Development (BUCLD 35). Somervillle, MA: Cascadilla Press, 616-27.

Vasić N, Chondrogianni V, Marinis T, and Blom E (2012) Processing of gender in TurkishDutch and Turkish-Greek L2 children. In: Biller AK, Chung EY, and Kimball AE (eds) Proceedings of the 36th Boston University Conference on Language Development (BUCLD 36). Somerville, MA: Cascadilla Press, 646-59.

Verbeek J, van den Dungen L, and Baker AE (2007) Spontane Taal Analyse Procedure: Verantwoording Van Het STAP-Instrument [Spontaneous language analysis procedure: Justification of the STAP instrument]. Amsterdam: Universiteit van Amsterdam, Faculteit der Geesteswetenschappen.

Verhoeven R and Vermeer A (2001) Taaltest Alle Kinderen (TAK) [Language assessment all children]. Arnhem: CITO.

White L (2003) Second Language Acquisition and Universal Grammar. Cambridge: Cambridge University Press.

White L (2009) Some questions about feature re-assembly. Second Language Research 25: 343-48.

Zdorenko T and Paradis J (2008) The acquisition of articles in child second language English: Fluctuation, transfer or both?. Second Language Research 24: 227-50.

Zdorenko T and Paradis J (2011) Articles in child L2 English: When L1 and L2 acquisition meet at the interface. First Language 21: 1-25. 